\title{
The Economic Impact of Originator-to-Biosimilar Non-medical Switching in the Real-World Setting: A Systematic Literature Review
}

\author{
Erin Hillhouse $\cdot$ Karine Mathurin · Joëlle Bibeau $\cdot$ Diana Parison • \\ Yasmine Rahal $\cdot$ Jean Lachaine $\cdot$ Catherine Beauchemin (D)
}

Received: July 7, 2021 / Accepted: October 6, 2021 / Published online: November 15, 2021

(C) The Author(s) 2021

\begin{abstract}
Introduction: To save costs to the healthcare system, forced non-medical switch (NMS) policies that cut drug coverage for originator biologics and fund only less expensive biosimilars are being implemented. However, costs related to the impact of NMS on healthcare resource utilization (HCRU) must also be considered. This study aims to summarize the evidence on the economic impact of an originator-tobiosimilar NMS.
\end{abstract}

Methods: A systematic literature review (SLR) was conducted. Publications reporting on HCRU or costs associated with originator-tobiosimilar NMS in the real-world setting were searched in MEDLINE and EMBASE from January 2008 to February 2020. In addition to hand searching the reference lists of relevant

Supplementary Information The online version contains supplementary material available at https:// doi.org/10.1007/s12325-021-01951-z.

E. Hillhouse $\cdot$ K. Mathurin $\cdot J$. Bibeau $\cdot$ J. Lachaine C. Beauchemin $(\square)$

PeriPharm Inc., 485 McGill St. Suite 910, Montreal, QC H2Y 2H4, Canada

e-mail: catherine.beauchemin@peripharm.com

K. Mathurin · J. Lachaine · C. Beauchemin

University of Montreal, Montreal, QC, Canada

D. Parison · Y. Rahal

AbbVie Corporation, St-Laurent, QC, Canada publications and SLRs, key conference websites, PubMed, and various government sites were also searched for the 2 years preceding the search (2018-2020).

Results: A total of 1845 citations were identified, of which 49 were retained for data extraction. Most studies reporting on the HCRU associated with NMS reported on post-NMS HCRU alone without a comparison pre-NMS. However, four studies described a difference in HCRU (i.e., investigations pre- vs post-switch or between non-switchers vs switchers), all of which reported a relative increase in HCRU, including laboratory testing, imaging, medical visits, and hospitalizations, amongst patients who underwent an originator-to-biosimilar NMS. Most studies reporting on the costs associated with NMS reported significant savings following NMS on the basis of drug costs alone. However, four studies specifically reporting on the difference of costs following originator-tobiosimilar NMS all demonstrated an increase in HCRU-related costs associated with NMS (increase in HCRU-related costs of $4-37 \%$ or 148-2234 2020 Canadian dollars).

Conclusion: Amongst the studies that reported on the difference in HCRU pre- vs post-switch or between non-switchers and switchers, all showed an increase in HCRU and related costs associated with NMS, suggesting that the expected overall savings due to less costly drug prices may be reduced as a result of an increase in HCRU and its associated costs post-switch. 
Nevertheless, more real-world studies that include NMS-related healthcare costs in addition to drug costs are needed.

Keywords: Biologics; Biosimilar; Drug costs; Non-medical switching; Resource utilization; Systematic literature review

\section{Key Summary Points}

Why carry out the study?

As a result of the high cost of biologics, there has been a push to move to biosimilars, which are similar to a biologic but sold at a much lower price.

Biologics and biosimilars are not identical in terms of structure, function, quality, clinical efficacy, and clinical safety; therefore, costs other than those associated with drug acquisition need to be considered.

In order to evaluate the true economic impact of introducing originator-tobiosimilar non-medical switching (NMS) policies in Canada, a systematic literature review (SLR) evaluating the healthcare resource utilization (HCRU) and costs associated with originator-to-biosimilar NMS in the real-world setting was performed.

\section{What was learned from the study?}

Originator-to-biosimilar NMS may result in an increase in HCRU and HCRU-related costs, such that the expected cost savings associated with originator-to-biosimilar NMS may be greatly reduced.

Future economic evaluations on this topic need to consider the costs associated with additional HCRU, not just drug costs alone, in order to properly inform the decision to adopt a NMS policy.

\section{INTRODUCTION}

A biologic drug is any pharmaceutical drug product whose components or precursors are manufactured in, extracted from, or synthesized from, a living organism, or their cells, such as humans, animals, plants, and fungal or microbial organisms [1]. Important biologic drugs include hormones, hematopoietic growth factors, thrombolytic agents, cytokines, therapeutic enzymes, and antibodies [1]. Biologics are used in the treatment of rheumatological diseases, such as rheumatoid arthritis (RA), and gastrointestinal diseases, such as Crohn's disease (CD) and ulcerative colitis (UC) [2-5]; they can also be used to treat patients suffering from other chronic conditions in the areas of dermatology, hepatology, oncology, and growth development [6-9]. For this reason, the discovery of biological therapies have made a substantial clinical impact on the Canadian healthcare system. Canada is known to have a high prevalence of many of these chronic conditions, such as UC, CD, RA, and psoriasis, having some of the highest rates reported worldwide. Additionally, as a result of an aging population, population growth, and increasing life expectancy, the incidence and prevalence of some of these conditions have been increasing in recent years [10-12].

While biologic drugs comprise various vital therapeutic options for patients, they can be very costly to the healthcare system. In 2018, sales of biologic drugs in Canada reached $\$ 7.7$ billion, placing Canada among the topranked countries in terms of per capita spending [13]. Biosimilars, on the other hand, are biologic medicinal products that are highly similar to a reference biologic drug that was already authorized for sale, and often sold at a lower price [1, 14-17]. Specifically in Canada, biosimilar drugs are sold at a reduced price that is, on average, $30 \%$ less than the price of the reference biologic $[13,18]$. Accordingly, in comparison to Remicade $^{\circledR}$, biosimilar infliximab drugs are associated with an approximate $30-40 \%$ decrease in the listed price [18].

Biosimilars can play a role in limiting the economic burden on the healthcare system and 
increasing patient access to biological treatments. Indeed, biosimilars can be offered at lower prices than the reference biologic and, in consequence, lead to price competition amongst biologic drugs [19]. Consequently, the adoption of biosimilars can help to liberate resources that could be used elsewhere by the healthcare system, such as for the reimbursement of innovative medicines [19]. A number of studies have also suggested that switching from a reference biologic to a biosimilar is not associated with any major efficacy, safety, or immunogenicity issues $[19,20]$. For these reasons, governments in some jurisdictions have or are planning on implementing forced nonmedical switch (NMS) policies by cutting drug coverage for reference biologics and funding only less expensive biosimilars. These NMS policies describe a plan whereby a stable patient's treatment regimen is changed for reasons other than efficacy, side effects, or adherence related to the original treatment [21]. Importantly, there has been ongoing debate as to whether or not the originator-to-biosimilar NMS is a viable option for patients that are successfully being treated with an originator biologic [21, 22]. Health Canada has authorized various biosimilars for sale in Canada and provinces have already introduced reimbursement policies for the utilization of biosimilars instead of the biologic originator for new patients. British Columbia announced in May 2019 a NMS policy that is expected to reduce costs by an estimated $\$ 96.6$ million over the first 3 years alone [23, 24]. Specifically, while treatmentnaïve patients will receive the biosimilar at treatment initiation, the NMS policy will force patients who are currently receiving the reference biologic to switch to the biosimilar drug regardless of disease activity. In December 2019, Alberta also announced the implementation of a similar originator-to-biosimilar NMS policy, while Ontario is taking steps towards realization of a similar policy $[25,26]$.

Although the introduction of biosimilars is expected to provide cost savings to the healthcare system, the impact of originator-tobiosimilar NMS on healthcare resource utilization (HCRU) and their associated costs is complex to assess. Importantly, biosimilars are often wrongly likened to generic drugs. Biosimilars are not generic drugs; they can never be exactly the same as their originator. Approved biosimilars are biotherapeutics that have been shown to have no clinically meaningful differences compared to their originator products. Therefore, when estimating the economic impact of originator-to-biosimilar NMS, one must consider indirect costs such as costs associated with additional healthcare resources including medical visits, laboratory tests, and phone consultations.

In 2019, Liu et al. published a systematic literature review (SLR) to retrieve studies that assessed the impact of NMS on HCRU and costs and found that the true economic impact of originator-to-biosimilar NMS remains uncertain as the focus of most studies remains on drug costs [27]. Liu et al. also concluded that more real-world studies focused on drug costs as well as the additional costs associated with HCRU are needed in order to accurately evaluate the overall economic impact of originator-tobiosimilar NMS. Considering the rapidly changing regulatory and market access framework for biosimilars, there are potentially several key studies reporting real-world data on originator-to-biosimilar NMS that have recently been published or presented at recent conferences. Consequently, an updated SLR on this topic, specifically in a real-world setting, is needed to provide more current evidence on the economic impact of introducing such NMS policies in Canada. Accordingly, the objective of this SLR was to systematically identify studies evaluating the HCRU or costs associated with originator-to-biosimilar NMS in the real-world setting.

\section{METHODS}

\section{Study Identification}

The literature search was performed in the MEDLINE and EMBASE databases using relevant keywords to identify published studies and conference proceedings reporting data associated with HCRU or costs associated with originator-to-biosimilar NMS, from January 2008 
until the time of the search (March 3, 2020). For MEDLINE and EMBASE, in order to better align with the precise SLR objective, a search filter was developed and based on the Canadian Agency for Drugs and Technologies in Health (CADTH) for economic evaluations/cost/economic models as well as the recent publication by Lui et al. (2019) in the Cochrane database of systematic reviews, entitled "Search strategies to identify observational studies in MEDLINE and Embase" [28]. The developed filter was supplemented with keywords regarding treatments of interest (i.e., biosimilar, originator, etc.), studies in the real-world setting (i.e., cohort, cross-sectional, real-world, longitudinal, retrospective, etc.), various terms related to HCRU and costs (i.e., health resources, economics, cost, etc.), and NMS (i.e., switch, alternative, launch, etc.). Any additional publications were identified by hand searching reference lists of relevant publications and previously published SLRs. Full details of the literature search are presented in Appendix 1 in the electronic supplementary material.

In order to identify relevant study results that might not have been indexed by EMBASE or MEDLINE at the time of the search, key conference proceedings of disease areas that may be treated with biologics/biosimilars were consulted for the 2 years preceding the search (2018-2020). In parallel, PubMed and government sites, namely National Institute for Health and Care Excellence (NICE), CADTH, and Canadian provincial sites (ex. Institut national d'excellence en santé et en services sociaux, Ontario Health Technology Advisory Committee, etc.) were searched for relevant reports for the same period (2018-2020). For conference proceedings, PubMed, and government sites, simple search terms (e.g., biosimilar, originator, switch) were used independently. A complete list of the conference websites is presented in Appendix 2 in the electronic supplementary material.

\section{Study Eligibility Criteria}

This SLR was conducted according to the Preferred Reporting Items for Systematic Reviews and Meta-Analyses (PRISMA) guidelines [29]. The review question was established using the PICOS framework (Population, Interventions, Comparators, Outcomes, Study Design). Specifically, the study population consisted of patients who underwent an originator-tobiosimilar switch for non-medical, or presumably non-medical, reasons (i.e., patient choice, all patients switched, patients switched irrespective of disease activity, patients with stable disease switched, financial reason), with no restrictions pertaining to patient age, gender, or disease area. Interventions included any biosimilar following treatment with the reference biologic. There was no restriction on the study comparator. The outcomes of interest included HCRU and any costs associated with originator-to-biosimilar NMS. This SLR was restricted to interviews, surveys, cohort studies, database studies, and patient-reported outcomes (PRO) studies in the real-world setting. Lastly, this SLR was limited to English publications, except when searching Québec provincial sites, namely Institut national d'excellence en santé et en services sociaux, for which French publications were also included. The SLR is based on previously conducted studies and does not contain any studies with human participants or animals performed by any of the authors.

\section{Study Selection}

Two reviewers independently screened titles and abstracts for relevance. Any citation/abstract deemed relevant by either reviewer was obtained in full-text form. Full-text articles and conference abstracts were then reviewed by both reviewers independently. Any publication failing to meet the eligibility criteria was excluded. In the case of duplicated publications on the same study, the most up-to-date publication was used. Discrepancies in study selection were resolved by consensus or with the help of a third reviewer. 


\section{Data Extraction}

Using a predefined extraction form, one reviewer extracted information from each eligible study, which was subsequently validated by a second reviewer to ensure accuracy. Data extracted from each publication and conference proceeding, if available, are shown in Table S1 in the electronic supplementary material. All costs were converted and inflated to 2020 Canadian dollars (\$C) using the general annual consumer price index [30].

\section{Study Quality Assessment}

The risk of bias of each individual selected study available in full-text form was assessed using the Cochrane Collaboration Risk of Bias in NonRandomized Studies-of Interventions (ROBINSI) [31].

\section{RESULTS}

\section{Search Results}

A flowchart of the selection process for the included studies is illustrated in Fig. 1. A total of 1845 studies were initially identified from the MEDLINE and EMBASE databases. After the exclusion of duplicates, 1720 studies were evaluated on the basis of title and abstract. Of them, 1242 were excluded on the basis of title selection and 425 were excluded on the basis of abstract selection. Of the 53 studies remaining, six were excluded for the following reasons: not real-world data $(n=1)$, not originator-tobiosimilar NMS $(n=1)$, no HCRU or costing data $(n=4)$. The search of conference websites and handsearching the reference lists of relevant publications resulted in two additional studies, namely one conference proceeding from each reference source. In total, 18 full-text publications and 31 abstracts were selected for data extraction.

\section{Description of Included Studies}

The study characteristics are described in Table 1 . The majority were center-based cohort studies $(n=41)$; other study types comprised interviews $(n=2)$, physician surveys as part of a simulation or decision tree model $(n=2)$, postmarketing $(n=1)$, and database $(n=3)$ studies. Most of the studies were from various countries in Europe $(n=43)$. Of note, only one study was based in North America, specifically the USA.

The disease areas identified were primarily in rheumatology $(n=19)$ and gastroenterology $(n=21)$. Infliximab was the sole biosimilar drug investigated in gastroenterology, while studies in rheumatology included infliximab $(n=5)$, rituximab $(n=1)$, and etanercept $(n=13)$. The patient populations and patient follow-ups varied considerably between studies. In gastroenterology studies, the mean number of patients studied was 92.6 (range 5-313) with a mean follow-up time of 13.6 months (range 6-60 months). In studies investigating rheumatology populations, the mean number of patients studied was 170.9 (range 25-1259) with a mean follow-up time of 9.2 months (range 4-15.8 months). Moreover, one study each was performed in dermatology (etanercept, 17 patients, 3-month follow-up), growth development (somatropin, 98 patients, followup not reported [NR]), hepatology (erythropoiesis-stimulating agent [ESA], 163 patients, 24 week follow-up), and oncology (filgrastim, 37 patients, follow-up NR). There were five included studies that either focused on multiple disease areas or did not specify the disease area. Lastly, amongst the 49 identified, eight citations reported on the costs associated with the implementation of a switch program at their center in addition to HCRU and/or costs postNMS.

\section{Healthcare Resource Utilization (HCRU)}

Nineteen studies reported on real-world HCRU associated with originator-to-biosimilar NMS (Table 2). Among them, 11 studies investigated gastroenterology patients, four investigated rheumatology, two investigated multiple 


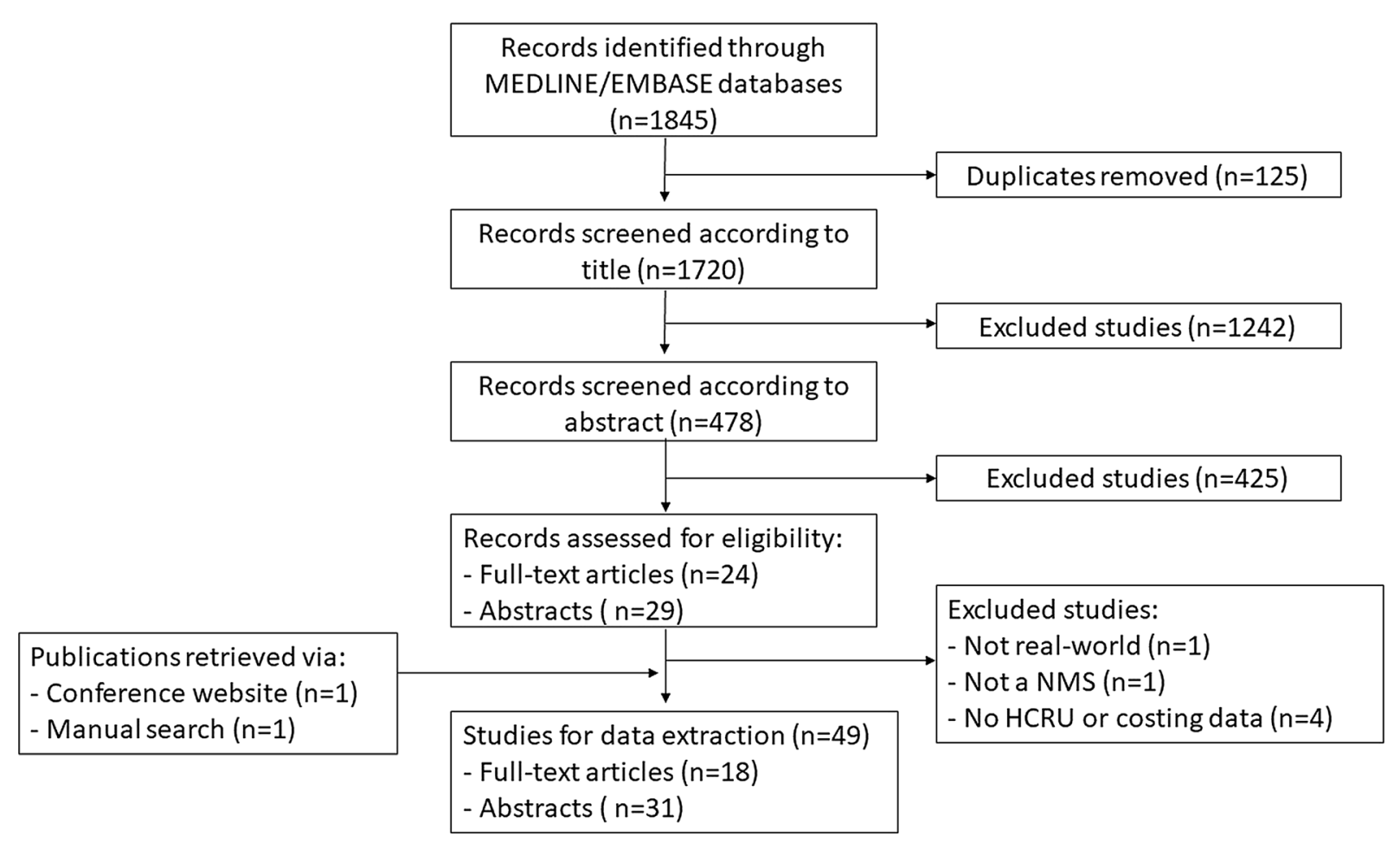

Fig. 1 Flow diagram of included studies

disease or unspecified areas, and there was one study each on oncology and growth development. The majority of these studies $(n=15)$ reported on HCRU during the follow-up period after NMS only; therefore, as there was no comparison to a study period or patient population without NMS, it cannot be concluded whether or not the reported utilization of healthcare resources was likely due to NMS in these studies. The 11 studies investigating gastroenterology patients demonstrated that hospitalizations and surgeries were common among patients following originator-to-biosimilar NMS; however, these studies did not show that these events were more, equally, or less likely to occur following NMS as there was no comparison to a pre-switch or non-switch population.

Four studies reported on real-world HCRU associated with originator-to-biosimilar NMS by describing the difference between patients preand post-switch or between patients who switched and those who remained on the reference biologic (i.e., switchers and non-switchers, respectively). Interestingly, all four of these studies reported an increase in HCRU with originator-to-biosimilar NMS, three of which were focused on rheumatology and the other on oncology. More specifically, they found that NMS can be associated with increased medical visits, medical services such as imaging, phone consultations, and emergency room (ER) visits, in addition to hospitalizations [6, 32-34].

In rheumatology, Tarallo et al. (2019) reported an increase in HCRU for rheumatology patients following NMS [32]. In this study, rheumatology specialists were surveyed and reported on a total of 1259 patients who switched from the etanercept reference biologic to an etanercept biosimilar. It was found that, in comparison to non-switchers, patients who switched to the biosimilar experienced an increase in the number of various services at both $0-3$ months and 4-6 months post-switch, which included blood tests, x-rays, ultrasounds, ER visits, specialist visits, and hospitalizations [32]. In line with these results, the studies by Gibofsky et al. (2019) and Glintborg et al. (2018) also found an increase, although marginal, in the number of outpatient visits post- 


\begin{tabular}{|c|c|c|c|c|c|c|c|c|c|c|c|c|c|}
\hline है & & $\tilde{z}$ & & $\tilde{z}$ & 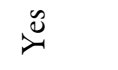 & $\tilde{z}$ & $\tilde{z}$ & $\tilde{z}$ & $\tilde{z}$ & $\tilde{z}$ & $\tilde{z}$ & $\tilde{z}$ & $\tilde{z}$ \\
\hline $\begin{array}{l}. \frac{\pi}{\omega} \\
\vdots \\
0 \\
0 \\
0\end{array}$ & & $\therefore$ & & 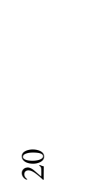 & $\stackrel{\circ}{=}$ & 구 & $\frac{m}{m}$ & $\mathbb{N}$ & $\stackrel{\Xi}{\Xi}$ & in & 8 & $\stackrel{\Re}{ \pm}$ & 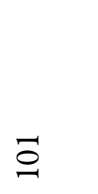 \\
\hline 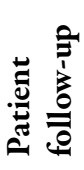 & & 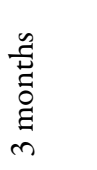 & & 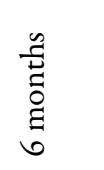 & 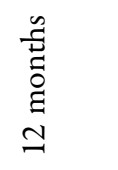 & 号 & 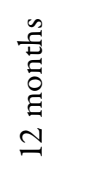 & 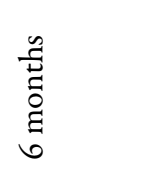 & 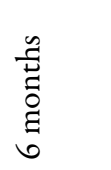 & 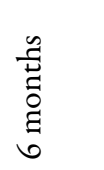 & 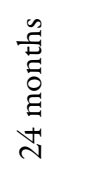 & 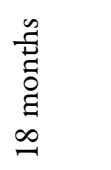 & $\begin{array}{l}\text { a } \\
\stackrel{1}{ \pm} \\
0 \\
\vdots \\
0\end{array}$ \\
\hline 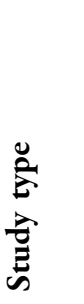 & & 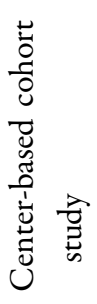 & & 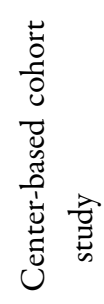 & 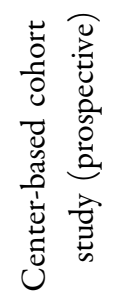 & 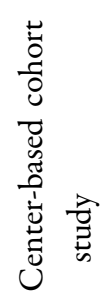 & 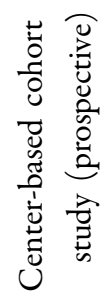 & 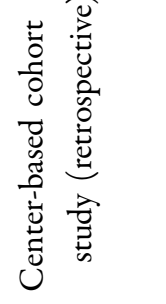 & 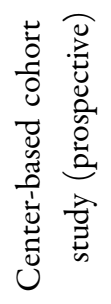 & 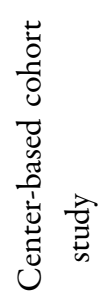 & 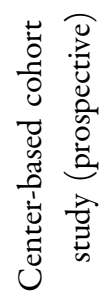 & 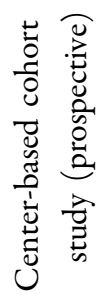 & 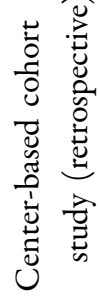 \\
\hline$\underbrace{\infty}_{0}$ & & 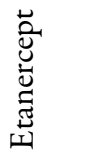 & & 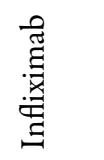 & 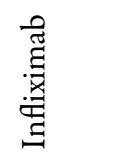 & 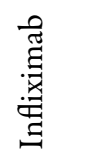 & 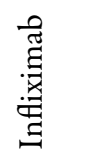 & 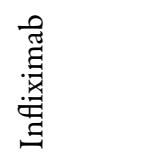 & 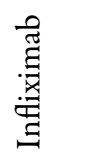 & 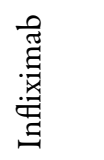 & 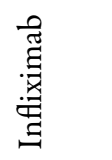 & 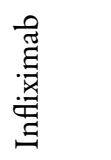 & 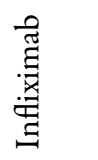 \\
\hline 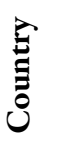 & & 光 & & 光 & 光 & 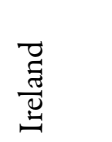 & 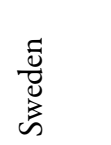 & 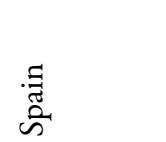 & 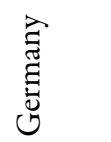 & 氖 & $\begin{array}{l}\tilde{\Xi} \\
\text { के }\end{array}$ & 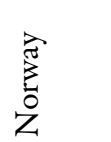 & 苛 \\
\hline 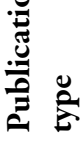 & & 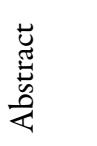 & & 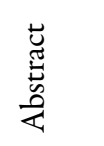 & 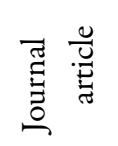 & 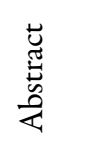 & 胥 & 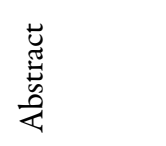 & 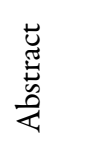 & 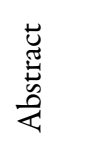 & 䧢 & 胥 & 胥 \\
\hline . & & 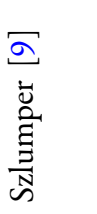 & & $\begin{array}{l}\text { 足 } \\
\stackrel{n}{\pi} \\
\text { 荌 }\end{array}$ & $\begin{array}{l}\frac{\pi}{ \pm} \\
\stackrel{n}{0} \\
\frac{0}{a}\end{array}$ & 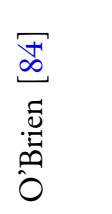 & 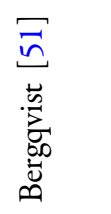 & 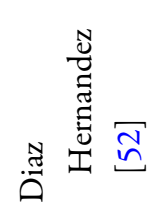 & 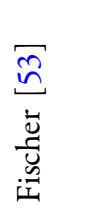 & 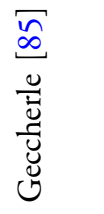 & 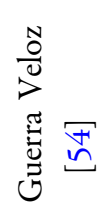 & 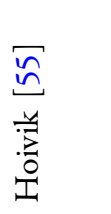 & $\begin{array}{l}\varpi \\
\infty \\
\vdots \\
\vdots\end{array}$ \\
\hline 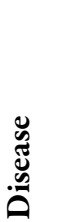 & $\begin{array}{l}\text { हूँ } \\
\text { है } \\
\text { है } \\
\text { है }\end{array}$ & 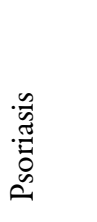 & 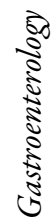 & 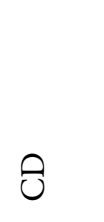 & త & $\stackrel{\oplus}{\oplus}$ & $\begin{array}{l}\dot{0} \\
\hat{0}\end{array}$ & $\begin{array}{l}0 \\
\dot{0} \\
\hat{0}\end{array}$ & $\begin{array}{l}\dot{0} \\
\hat{0}\end{array}$ & $\begin{array}{l}0 \\
\dot{0} \\
\hat{0}\end{array}$ & $\begin{array}{l}\hat{0} \\
\hat{0}\end{array}$ & $\begin{array}{l}\dot{0} \\
\dot{0}\end{array}$ & $\begin{array}{l}0 \\
\dot{0} \\
\hat{0}\end{array}$ \\
\hline
\end{tabular}




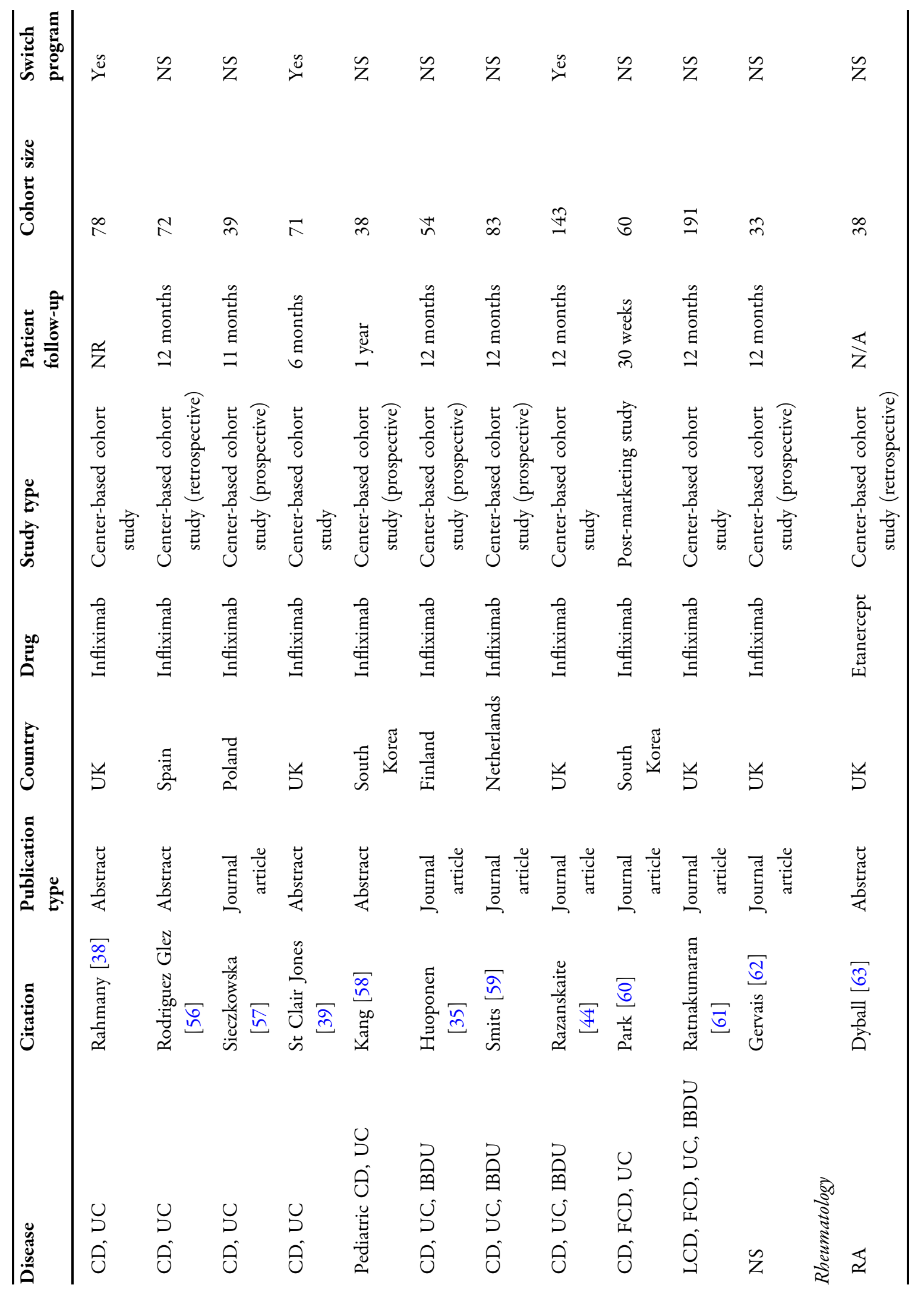




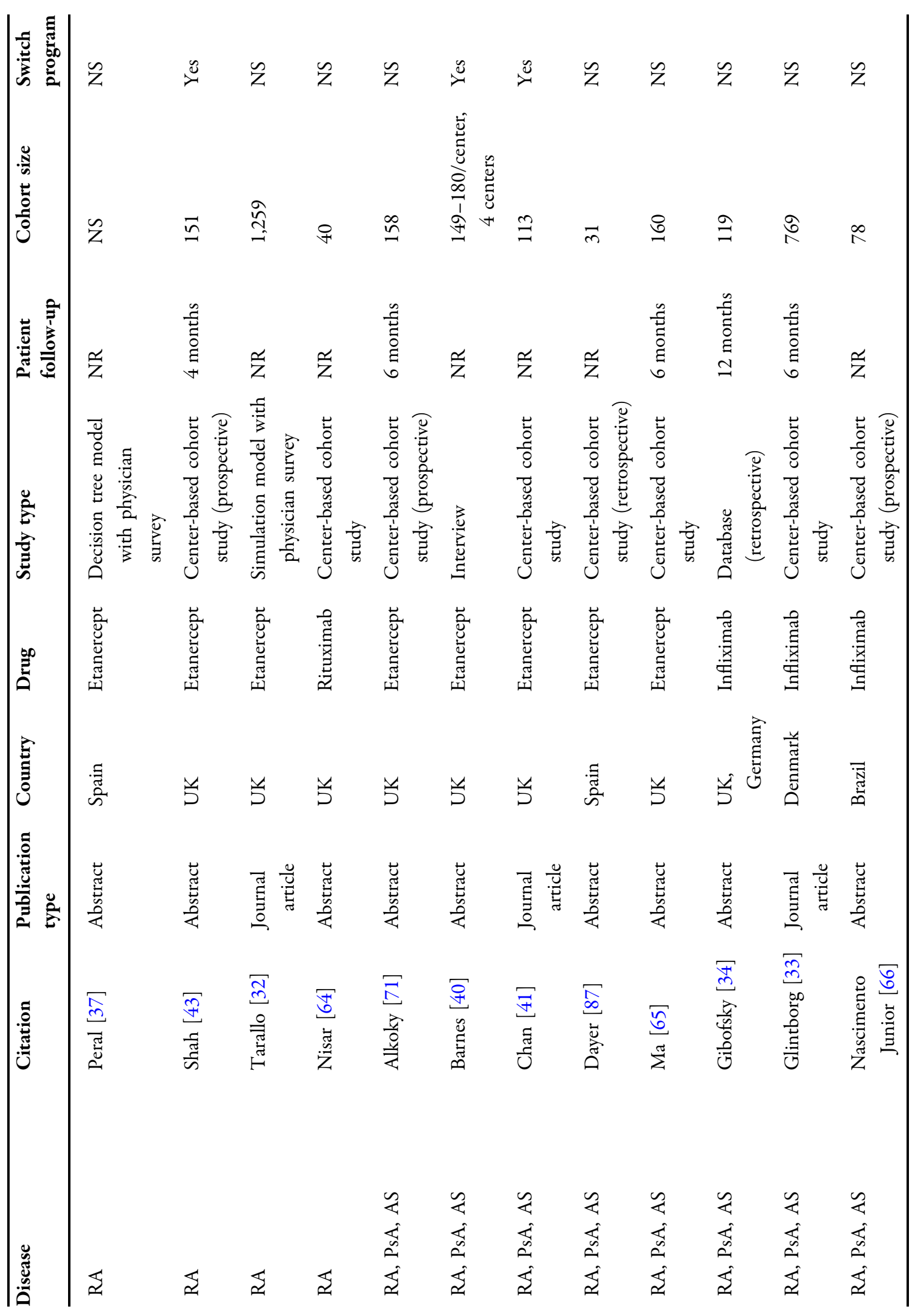




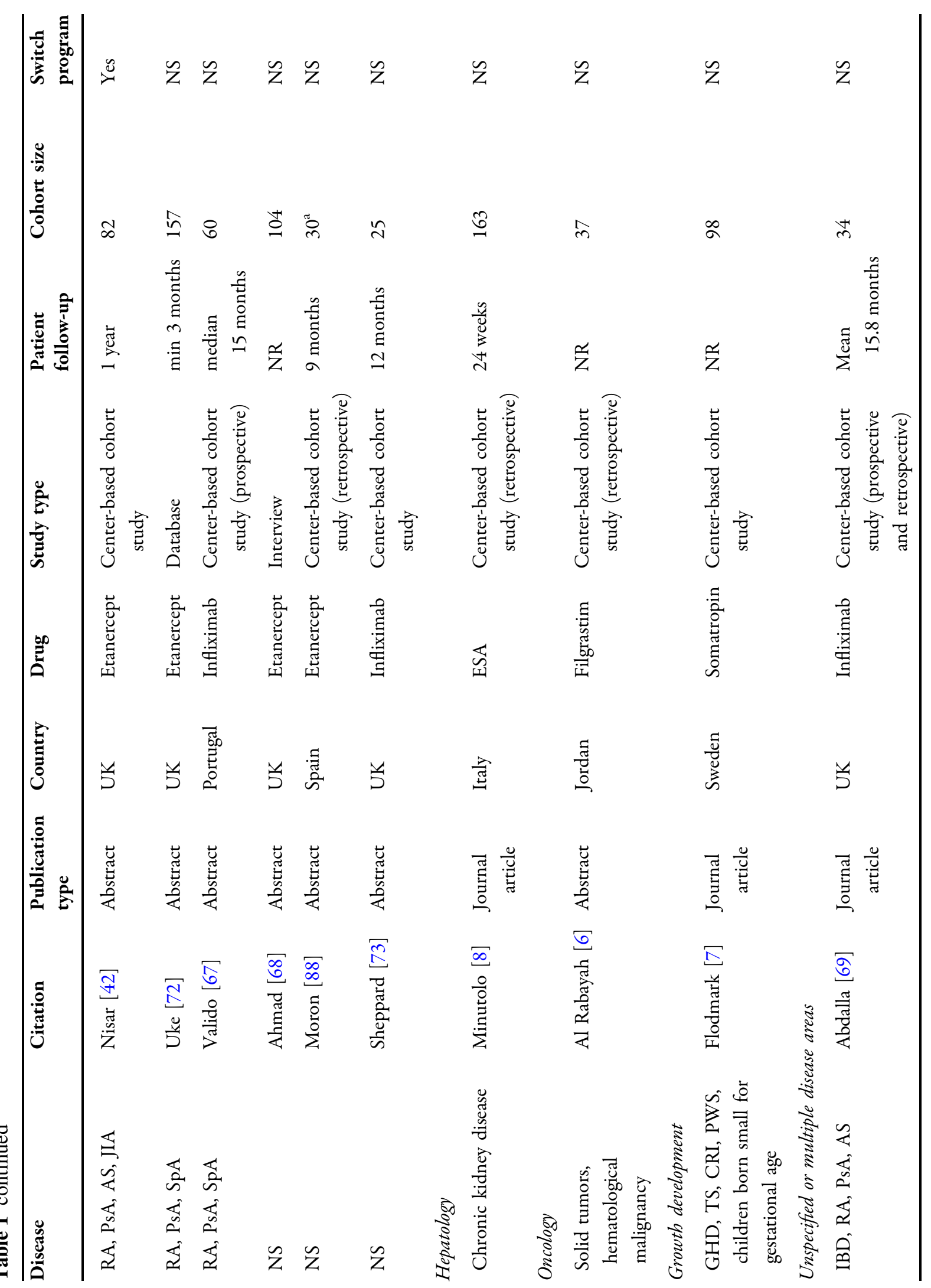




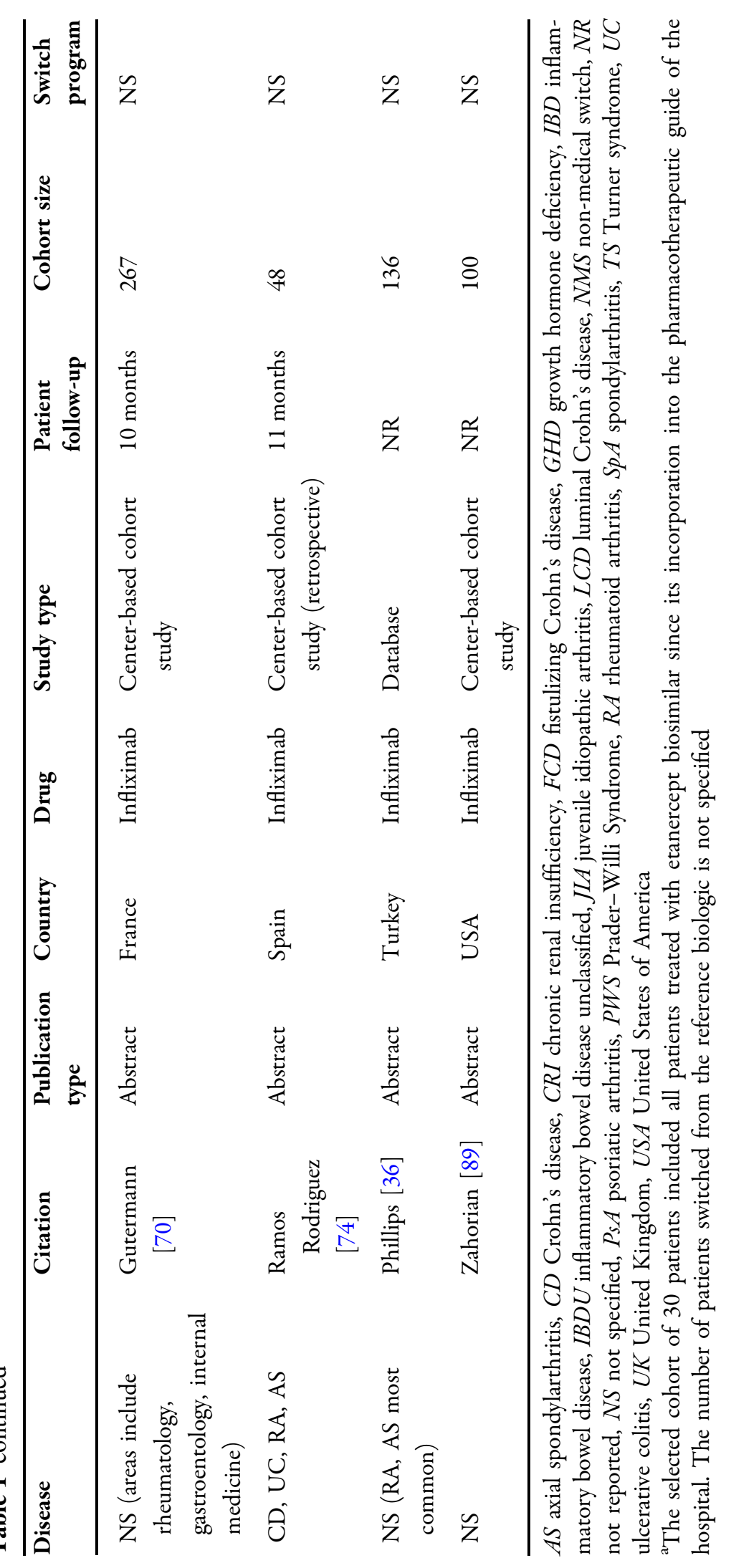




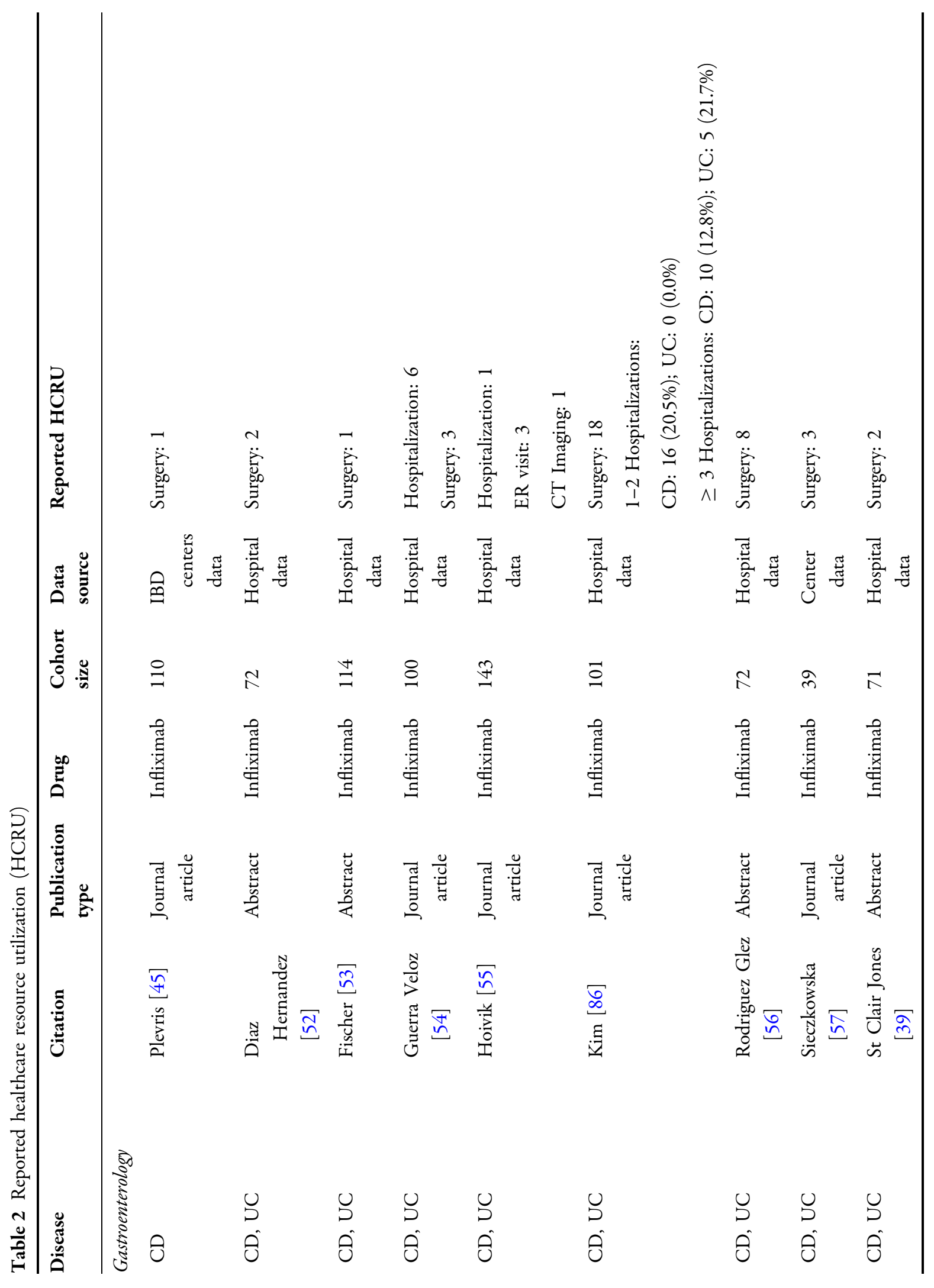




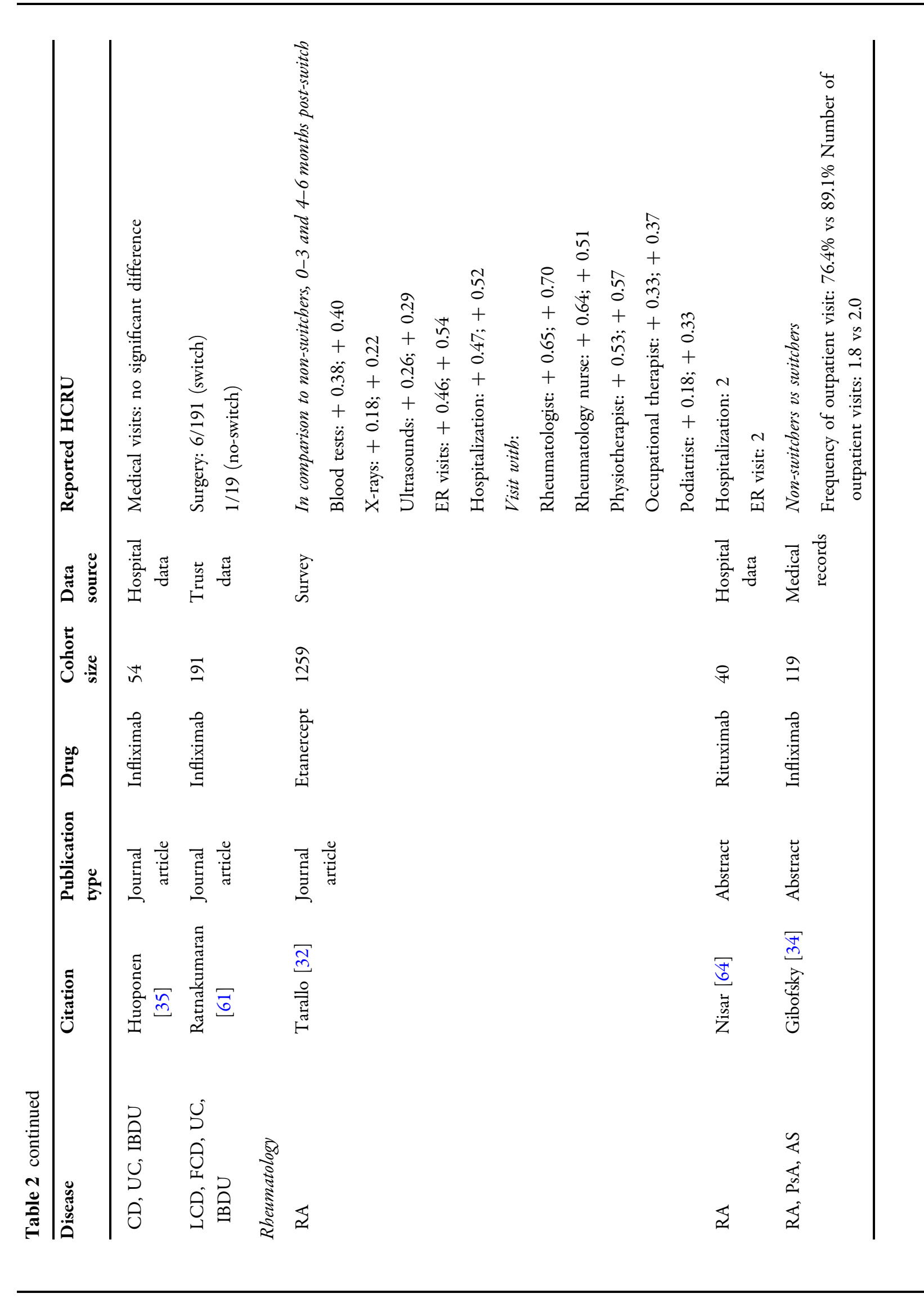




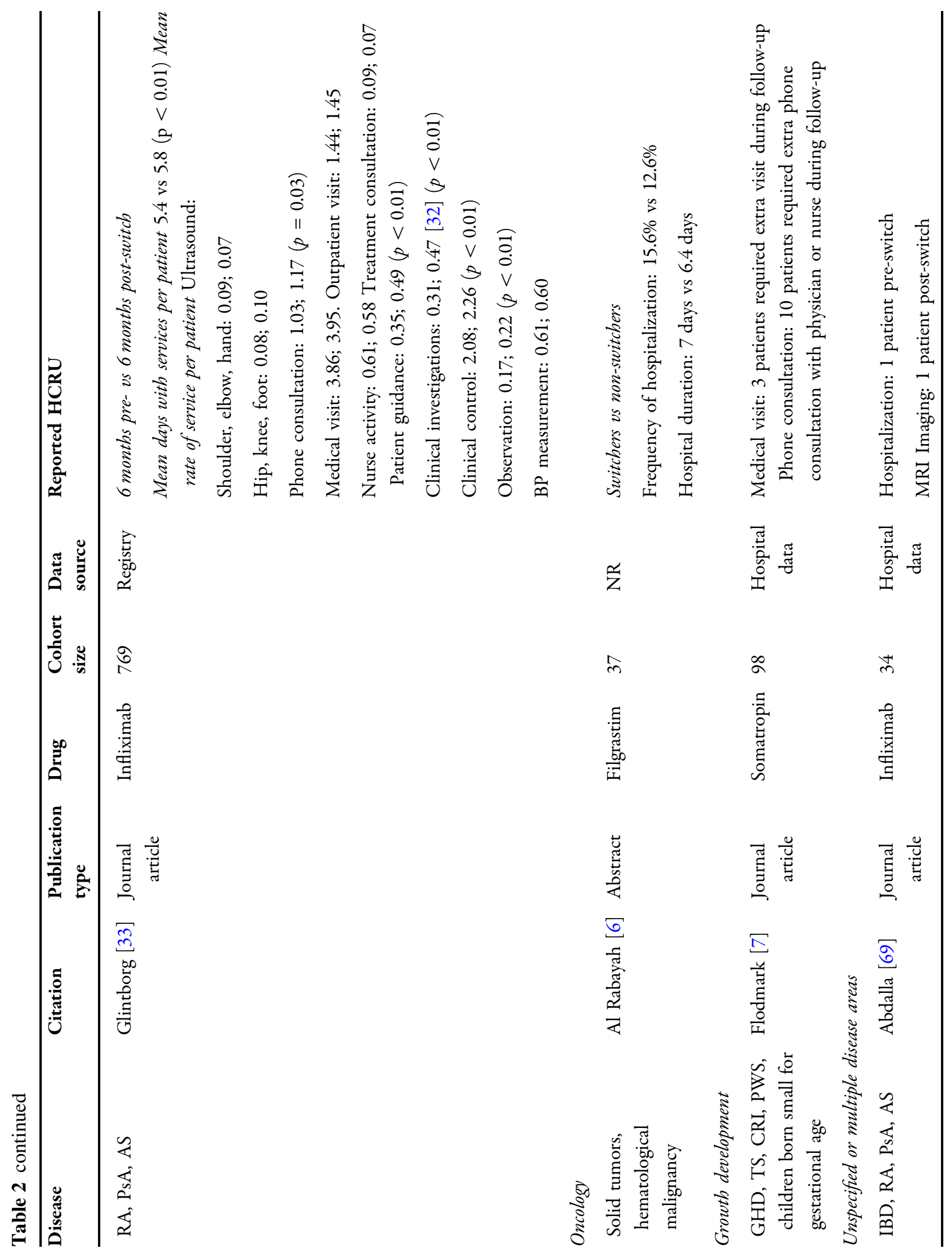




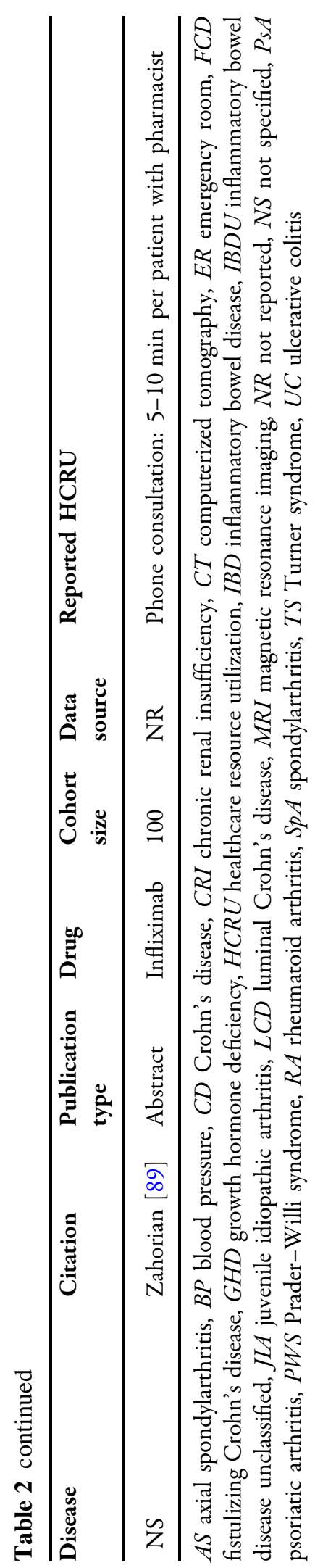

NMS for rheumatology patients, including RA, psoriatic arthritis, and axial spondylarthritis $[33,34]$. The difference in outpatient visits for patients with rheumatic disease associated with NMS was greater in the study by Tarallo et al. (an increase ranging from 0.18 to 0.70 over 3 months) in comparison to both Gibofsky et al. and Glintborg et al. (an increase of 0.2 over 3 months and 0.01 at 6 months post-switch vs 6 months pre-switch, respectively) [32-34]. Once again similar to Tarallo et al., the study by Glintborg et al. (2018) reported a significant increase in the utilization of various healthcare resources, albeit different resources than those reported in Tarallo et al. (2019), following infliximab NMS [33]. In comparison to 6 months pre-switch, Glintborg and colleagues found a significant increase in the total number of days with healthcare services 6 months postNMS, with a mean of 5.4 days (standard deviation [SD] 2.8) versus 5.8 days (SD 2.8), respectively $(p<0.01)$. With regards to the specific services, patients had more phone consultations (1.17 vs $1.03, p=0.03)$, patient guidance (0.49 vs $0.35, p<0.01)$, clinical investigation ( 0.47 vs $0.31, p<0.01)$, clinical control (2.26 vs 2.08 , $p<0.01)$, and observation $(0.22$ vs 0.17 , $p<0.01$ ) within 6 months following NMS in comparison to 6 months pre-switch, respectively [33]. Together, these studies demonstrated that while some healthcare resources may remain unchanged, other healthcare resources may significantly increase following originator-to-biosimilar NMS in rheumatic patients.

In an oncology study, Al Rabayah et al. (2018) also found an increase in both the frequency and duration of hospitalizations among patients who switched to a biosimilar in comparison to those who remained on the reference biologic ( $15.6 \%$ vs $12.6 \%$ and 7 days vs 6.4 days, respectively, follow-up period not specified) [6].

\section{Non-medical Switching-Related Costs}

Thirty-three studies reported on real-world HCRU-related and drug-related costs associated with NMS (Table 3). Among them, 13 studies investigated gastroenterology patients, 15 


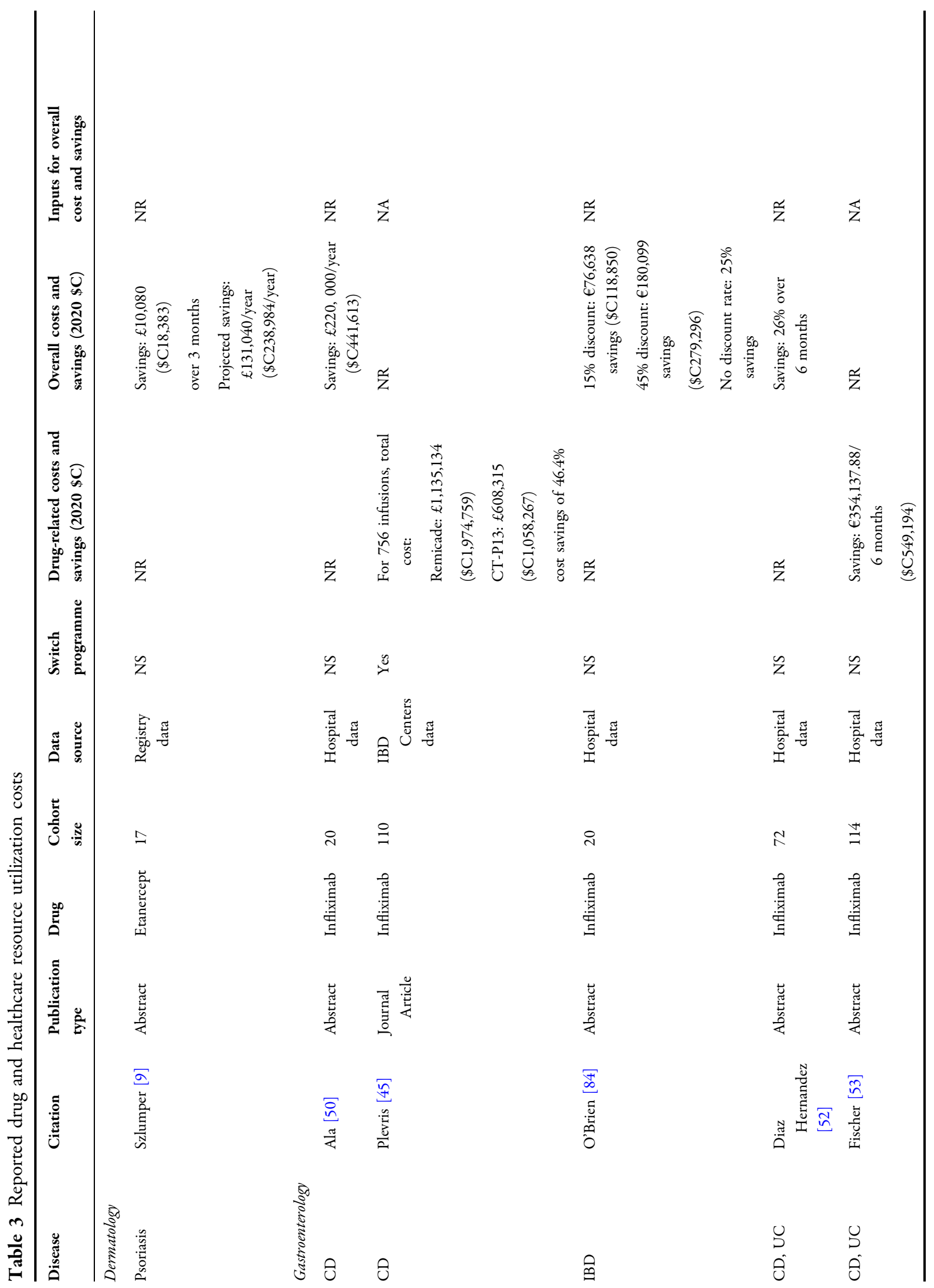




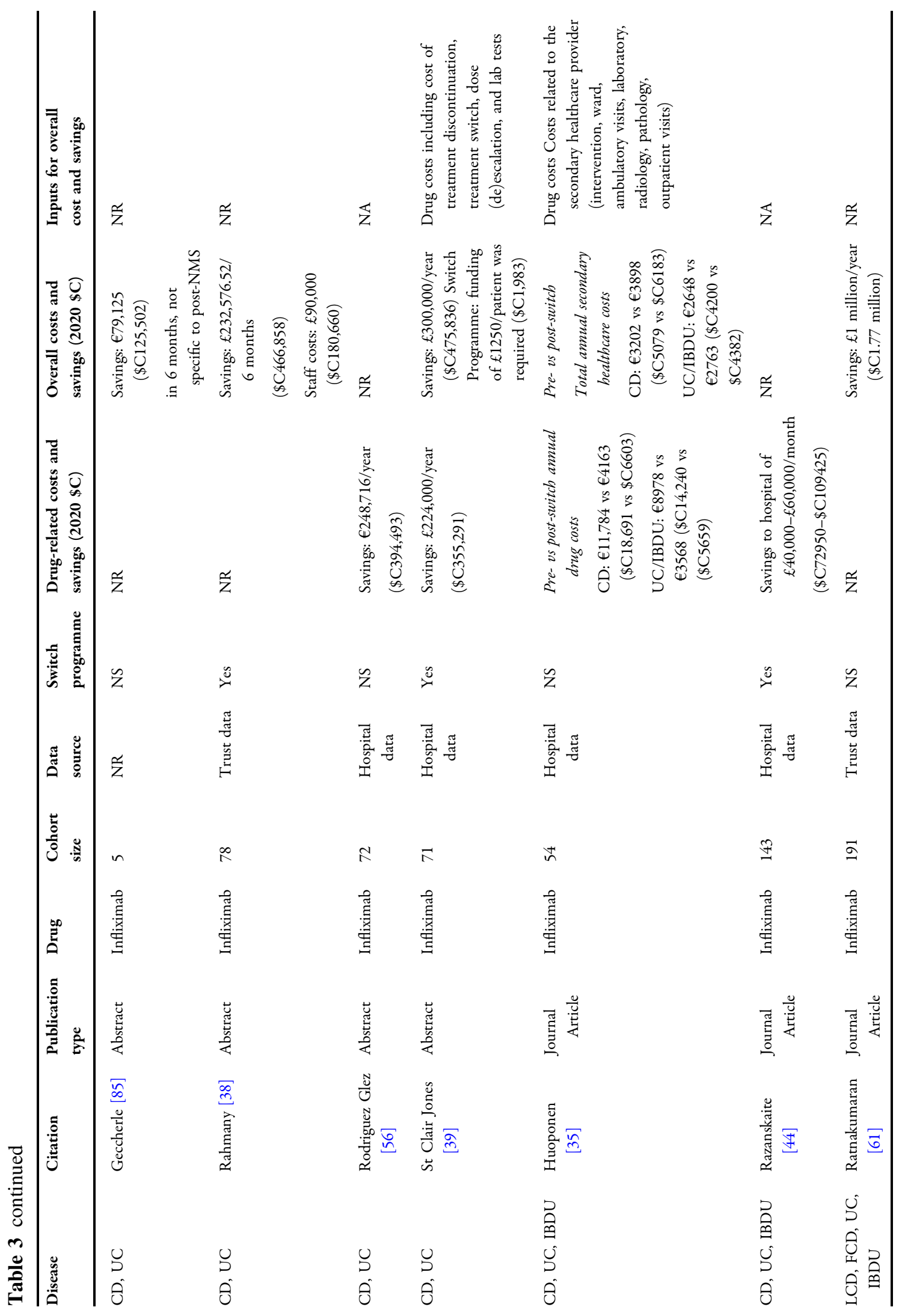




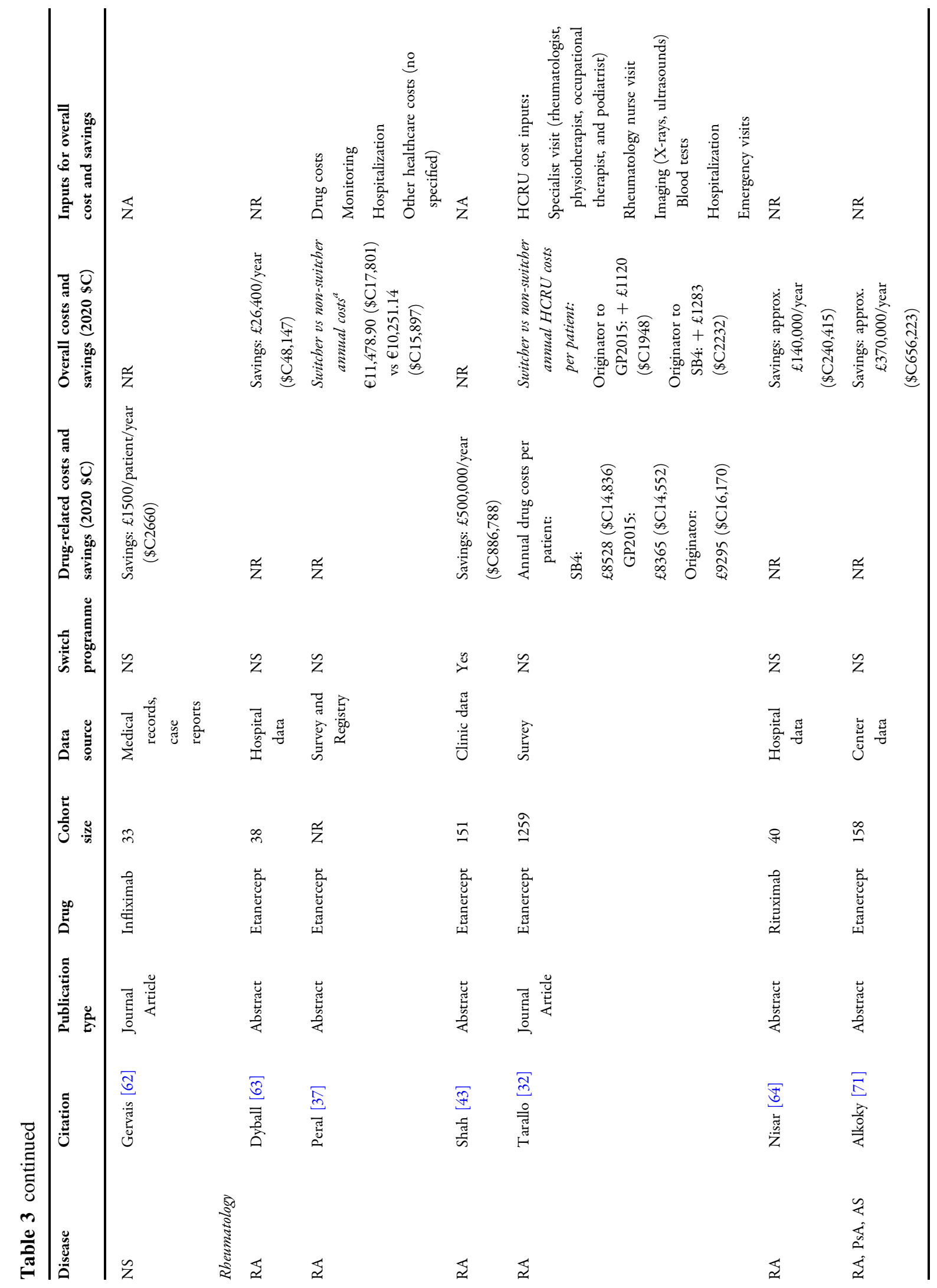




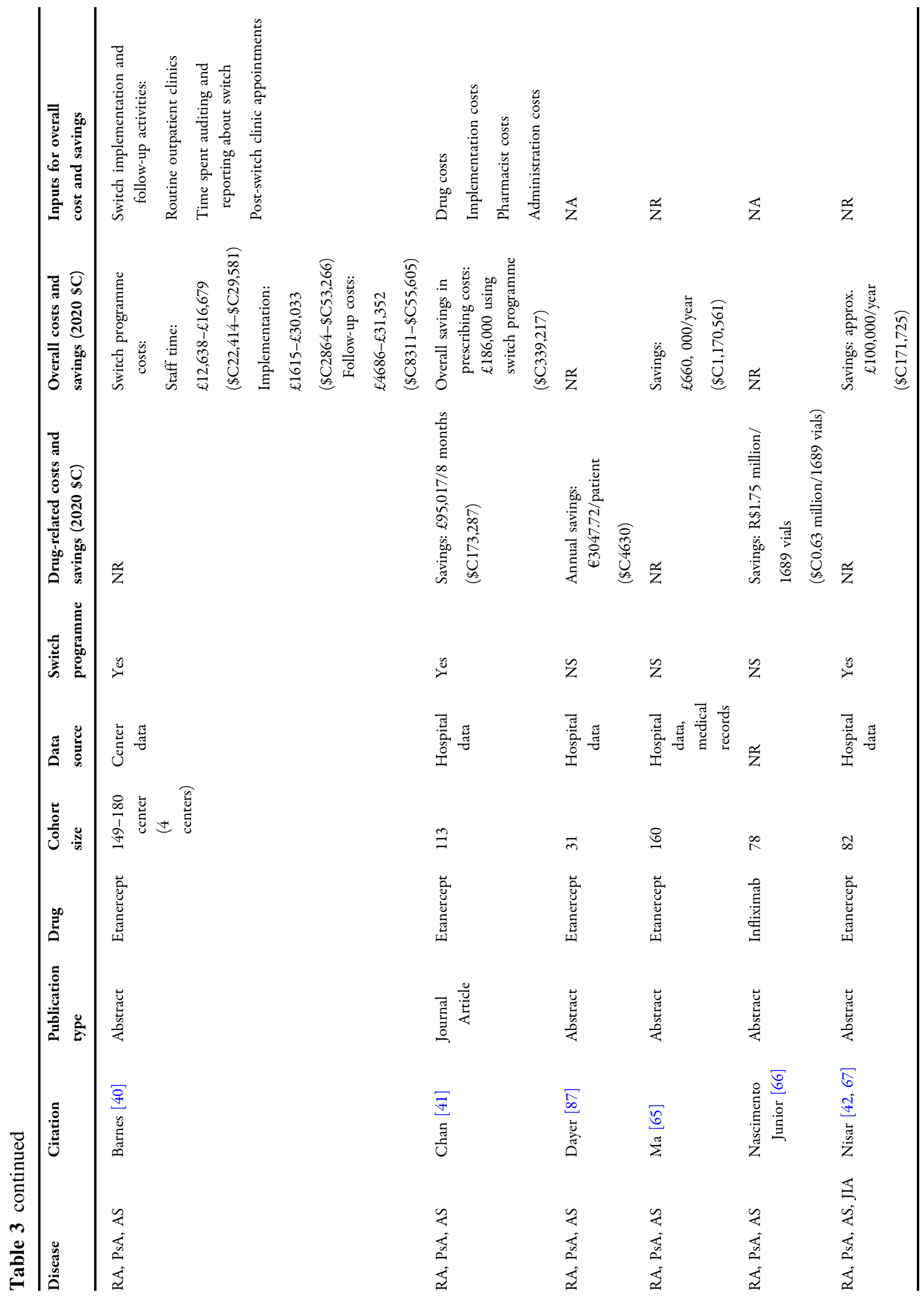




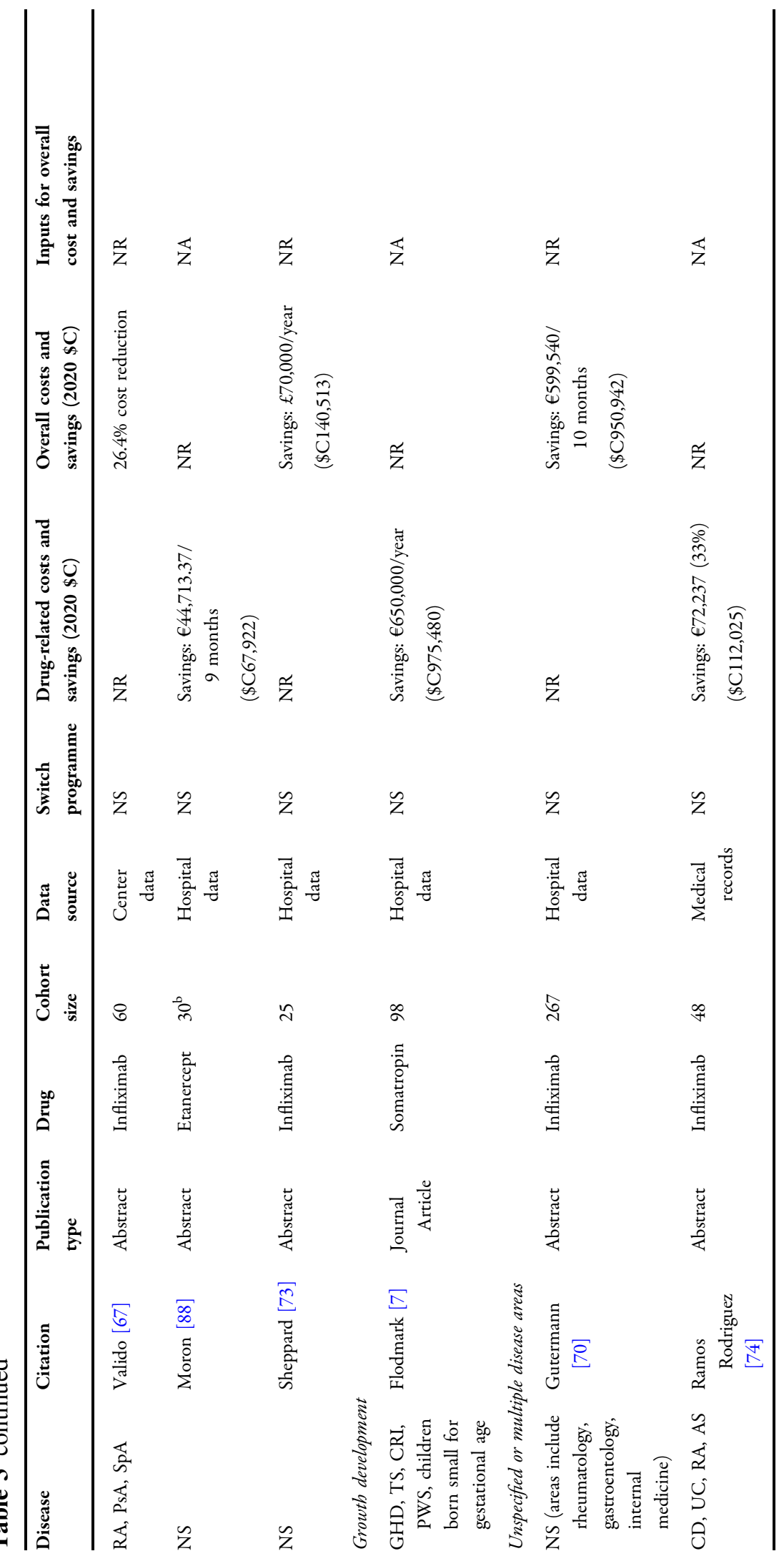




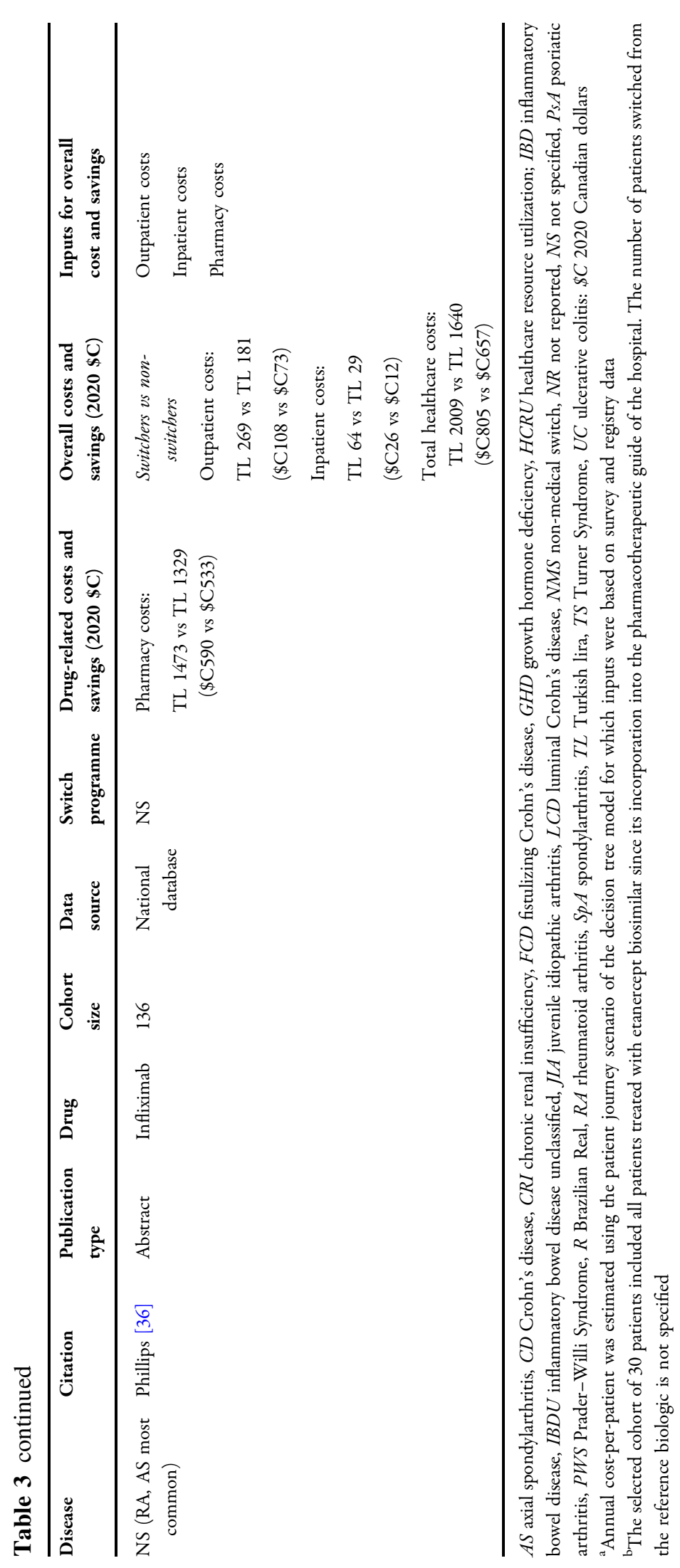




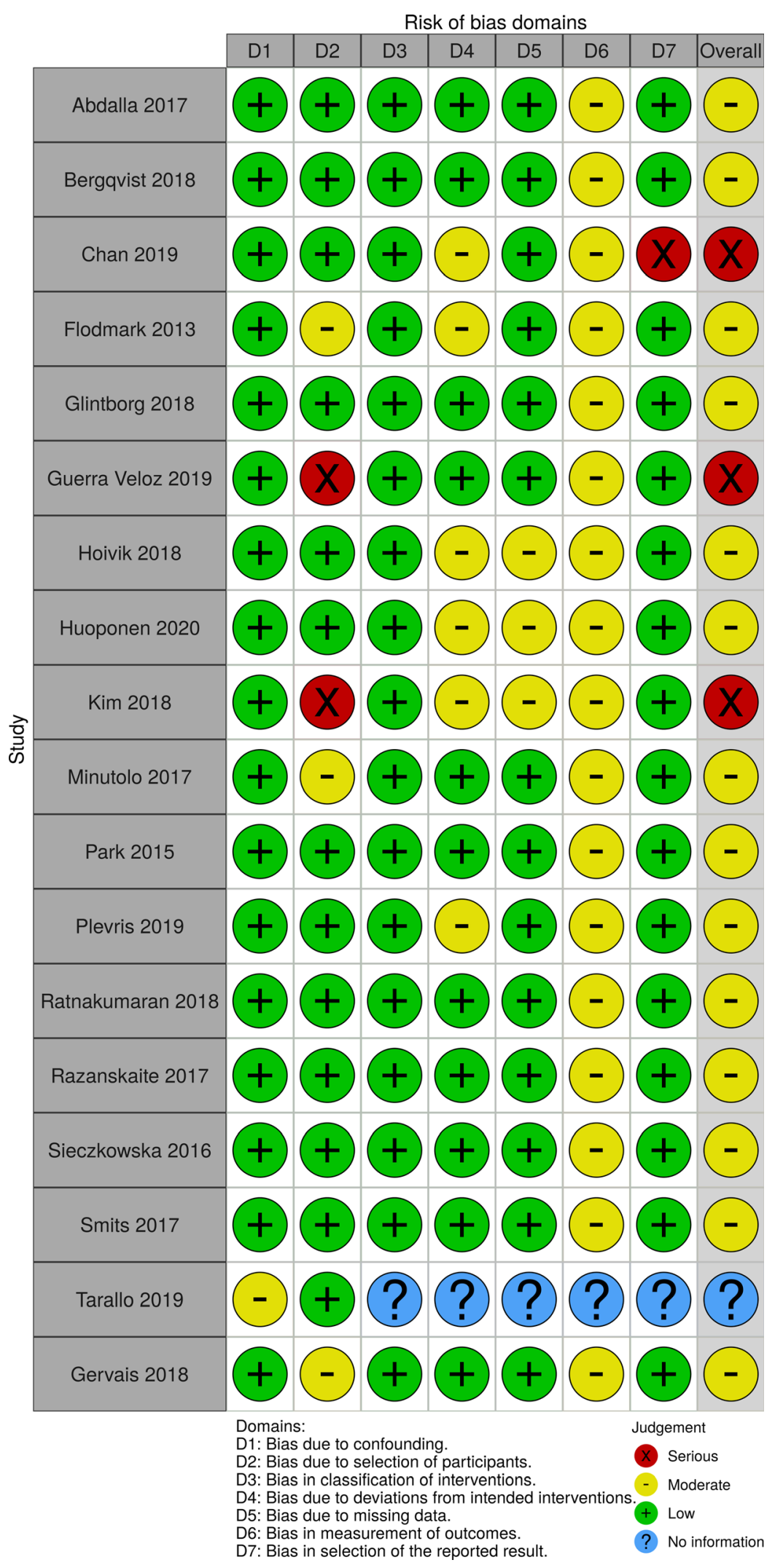


४Fig. 2 Risk of bias assessment

nvestigated rheumatology, three investigated unspecified or multiple disease areas, and there was one study each on dermatology and growth development. The majority of these studies reported on the savings associated with drug costs alone or the overall savings following NMS without specifying the inputs used for the calculations; however, four of these studies reported on the difference in costs between patients pre- and post-switch $(n=1)$ or between patients who switched and those who remained on the reference biologic (i.e., switchers and nonswitchers, respectively, $n=3$ ) [32, 35-37].

With regards to infliximab originator-tobiosimilar NMS, a recent publication by Huoponen et al. (2020) assessed the economic impact of the switch among gastroenterology patients by comparing costs pre- and postswitch [35]. While Huoponen et al. (2020) found substantial cost savings when taking into account drug costs alone for either CD (preswitch $=€ 11,784 \quad[\$ C 18,691] /$ year vs postswitch $=€ 4163$ [\$C6603]/year, a 65\% reduction in drug cost) or UC and inflammatory bowel disease unclassified (IBDU) (pre-switch $=€ 8978$ $[\$ C 14,240] /$ year vs post-switch $=€ 3568$ [\$C5659]/year, a 60\% reduction in drug cost), the HCRU-related costs were numerically greater in patients following NMS. While not as significant as the savings gained as a result of reduced biosimilar drug costs, the total annual secondary healthcare costs following NMS in patients with $\mathrm{CD}$ and UC/IBDU were $€ 3898$ (\$C6183) and $€ 2763$ (\$C4382), respectively, in comparison to $€ 3202$ (\$C5079) and $€ 2648$ (\$C4200), respectively, prior to NMS, amounting to an increase in total healthcare costs ranging from $4 \%$ to $22 \%$ [35]. Phillips et al. (2017) used the Turkish healthcare database to investigate the difference in costs for infliximab originator-to-biosimilar switchers versus nonswitchers, which mostly included patients with ankylosing spondylitis or RA [36]. They found a greater overall healthcare cost associated with patients who switched to the infliximab biosimilar in comparison to those who remained on the reference biologic (Turkish lira [TL] 2009 vs TL 1640 [\$C805 vs \$C657], respectively), amounting to an overall increase in healthcare costs of $23 \%$, which was determined on the basis of an increase in outpatient costs, inpatient costs, and overall pharmacy costs (TL 269 [\$C108] vs TL 181 [\$C73], TL 64 [\$C26] vs TL 29 [\$C12], and TL 1473 [\$C590] vs TL 1329 [\$C533], respectively) [36]. With regards to etanercept originator-to-biosimilar NMS, Peral et al. (2018) found that, using a decision-tree model with physician survey input, switching from etanercept to the biosimilar leads to a higher annual cost per patient $(+€ 1227.75$ [\$C1904], $+12.0 \%)$ in comparison to those remaining on the reference biologic to treat RA [37]. These results were corroborated by the findings of Tarallo et al. (2019), who published results of a physician survey of 1259 patients with RA who switched from etanercept to the biosimilar [32]. Tarallo et al. (2019) found that the difference in drug costs alone led to an annual drug costs savings of $8.2 \% \quad(£ 767 \quad[\$ \mathrm{C} 1334])$ to $10.0 \% \quad(£ 930$ [\$C1618]) per patient following NMS to etanercept biosimilar, but that the switch generated an increase in annual HCRU-related costs of $£ 1120$ (\$C1948) to $£ 1283$ (\$C2232) per patient, amounting to an increase of $32 \%$ to $37 \%$ in total costs per patient following NMS, which is greater than the savings attributed to drug costs alone [32]. Although biosimilars are expected to provide savings to healthcare systems, these studies suggested that, when taking into account HCRU-related costs in addition to drug costs, the overall savings associated with originator-to-biosimilar NMS are either reduced or eliminated resulting in an increase, rather than decrease, in the annual costs per patient.

Another factor that must be considered in the costs associated with originator-to-biosimilar NMS is the establishment of a switch program. Eight studies reported on the costs associated with the implementation of a switch program within their center (Table 1) [38-45]. Four of these studies, namely Razanskaite et al. (2017) [44], Shah et al. (2018) [43], Chan et al. (2019) [41], and Plevris et al. (2019) [45], reported substantial savings that were 
calculated using drug costs alone (Table 3). In addition, Nisar et al. (2019) stated an overall annual savings of approximately $£ 100,000$ $(\$ C 171,725)$ without specifying the inputs used in the calculations [42]. The three remaining studies reported on the specific costs generated by the switch program. St Clair Jones et al. (2017) found that the savings related to yearly drug costs amounted to $£ 224,000$ ( $\$ C 355,291$ ) and an overall savings of $£ 300,000(\$ C 475,836)$; however, in order to fund a specialist IBD nurse, the program also required a one-time fee of $£ 1250$ (\$C1983) in funding per patient [39]. Rhamany et al. (2016) also reported substantial savings of more than $£ 200,000 \quad(\$ C 343,450)$ over a 6-month period, though the authors also specified an additional staff cost of $£ 90,000$ $(\$ C 180,660)$ over the 6-month period associated with the program [38]. Barnes et al. (2018) reported on various costs associated with different aspects of the switch program, including additional staff time (£12,638 to $£ 16,679$ [\$C22,414 to $\$ C 29,581]$ ), implementation of the program ( $£ 1615$ to $£ 30,033$ [ $\$ \mathrm{C} 2864$ to $\$ C 53,266]$ ), and patient follow-up ( $£ 4686$ to $£ 31,352$ [\$C8311 to \$C55,605]) [40]. Therefore, while the implementation of switch programs are expected to provide cost savings to the healthcare system, the calculations are often based on drug costs alone. Accordingly, the inclusion of other factors, such as additional staff time and program funding, reduces the anticipated cost savings associated with originator-to-biosimilar switch programs.

\section{Study Quality}

The general risk of bias of the included full-text articles, according to the Cochrane Collaboration ROBINS-I tool, is presented in Fig. 2. Of the 18 published journal articles, the overall risk of bias was rated as moderate for 14 citations, serious for three citations, and unclear for one citation. Of note, each citation, except for Tarallo et al. (2019), which could not be assessed for the domain, was evaluated as a moderate risk of bias for domain 6 , which pertains to the measurement of outcomes. As both the patients and physicians were not blinded to treatment allocation (i.e., NMS) in a clinical setting, a moderate risk of bias was considered for most studies as it is possible that outcome measures or answers to survey questions were influenced by the knowledge of the intervention received by the patients. As the overall risk of bias is judged as moderate when a moderate risk is determined for at least one of the domains, the overall risk of bias was, consequently, considered as moderate for the majority of included studies.

\section{DISCUSSION}

While the introduction of biosimilars is expected to provide cost savings to the healthcare system, the economic impact of originator-tobiosimilar NMS is complex to assess. While highly similar, Health Canada authorization of biosimilar drugs does not signify equivalence to, or interchangeability with, the reference biologic drug [1]. Consequently, additional costs, such as those related to HCRU, in addition to drug acquisition costs, need to be taken into account when estimating the economic impact of originator-to-biosimilar NMS. In 2019, Liu et al. published a SLR evaluating the economic impact of originator-to-biosimilar NMS [27]. The authors stated that their review retrieved more data on anticipated cost estimates (i.e., generated from simulation studies) than on real-world observed post-NMS HCRU and costs. As a result, this SLR focused on realworld data in order to evaluate the economic impact of originator-to-biosimilar NMS in a real-word setting.

In the current SLR, we found many studies that focussed on savings related to drug costs alone without taking HCRU-related costs into account. Moreover, few studies investigated the difference in HCRU or costs associated with originator-to-biosimilar NMS, where findings were presented for patients both prior to and following the switch or were presented for patients who underwent NMS in comparison to patients that remained on the reference biologic. While these studies were scarce, they provided a better understanding of the savings or costs that were associated with the switch 
from the reference biologic to the biosimilar drug. Specifically, three studies reported on HCRU differences [6, 33, 34], three studies reported on cost differences [35-37], and one study reported on differences in both HCRU and overall costs [32]. With regards to HCRU, all studies concluded that NMS was associated with a significant or numerical increase in HCRU among patients who underwent originator-tobiosimilar NMS [6, 32-34]. Interestingly, there was a notable difference between studies in terms of outpatient visits associated with NMS, where this was greater for the study by Tarallo et al. in comparison to both Gibofsky et al. and Glintborg et al. (an increase in outpatient visits per patient of 0.18 to 0.70 versus 0.2 and 0.01 , respectively) [32-34]. Study differences that may account for this variation may include study design, where Tarallo et al. reported results of a physician survey whereas Gibofsky et al. and Glintborg et al. obtained medical records and registry data, respectively, or the drug examined, where Tarallo et al. examined etanercept, which is administered subcutaneously, whereas Gibofsky et al. and Glintborg et al. both examined infliximab, which is administered intravenously [32-34]. In contrast, Peral et al. (2018), Tarallo et al. (2019), and Phillips et al. (2017) found that a NMS from originator etanercept or infliximab to the biosimilar in rheumatic patients generated an overall increase in total costs to patients in comparison to remaining on the originator $(p=0.046$ in Phillips (2017), unreported in Peral (2018) and Tarallo (2019)) [32, 36, 37]. Importantly, Tarallo et al. identified blood and imaging tests, emergency visits, hospitalizations, and visits with various specialists as the primary healthcare costs leading to the increase in total patient costs following NMS [32]. Altogether, these studies suggested that post-NMS costs can, at times, be greater than the savings attributed to drug costs following a switch from the reference biologic to the biosimilar drug, such that NMS can result in an increase, rather than the anticipated decrease, in total costs per patient, at least in the short-term. Total costs per patient in the long-term following an originator-to-biosimilar NMS remain to be elucidated. Accordingly, potential long-term savings generated from an originator-to-biosimilar NMS could increase resources for the reimbursement of innovative drugs, which could be beneficial to patients. Altogether, as the patient populations of interest are dealing with chronic conditions, studies evaluating HCRU and costs in the long-term would provide much needed information. However, these analyses can prove challenging as, particularly in immunologic conditions, patients often lose response and switch to more expensive therapy, which may limit the long-term cost differences associated with NMS to a more finite time horizon.

In Canada, biosimilar drugs are sold at a reduced price that is, on average, $30 \%$ less than the price of the reference biologic [13, 18], suggesting that originator-to-biosimilar NMS policies result in savings to the Canadian healthcare system. However, understanding the full economic impact of introducing originatorto-biosimilar NMS policies in Canada requires the consideration of HCRU-related costs associated with NMS as well. In order to better understand the costs associated with originatorto-biosimilar NMS in Canada, HCRU-related costs associated with NMS, based on the HCRU data retrieved from this current SLR, were estimated from a Canadian perspective [46]. Using unit costs from Canadian governmental sources and published literature, it was determined that, over a 6-month period, rheumatic patients who underwent originator-to-biosimilar NMS incurred greater HCRU-related costs, estimated at an additional \$1317 per patient, compared to those who stayed on the originator biologic. In this analysis, the main drivers of the difference in costs between switchers and non-switchers were hospitalization costs and productivity loss [46].

The results of the current SLR are in line with those of Liu et al. [27]. While Liu et al. found that many studies demonstrated a cost reduction associated with NMS, the authors noted that many of these same studies were largely limited to drug costs alone and did not take into consideration the costs related to HCRU. When Liu et al. isolated the real-world studies that reported on NMS-related costs, aside from drug costs alone, the authors found that originatorto-biosimilar NMS was associated with 
increased HCRU and HCRU-related costs. More specifically, Liu et al. emphasized three realworld database studies identified in their search, two of which pertained to the same study by Glintborg et al. [33] and the other to the conference abstract by Phillips et al. [36], both of which were also identified and highlighted in the current SLR. Liu et al. concluded by emphasizing the need for more real-world studies that include both drug costs and other NMS-related costs in order to appreciate the full economic impact of NMS in both the short and long term.

Additional factors can also have an impact on the costs associated with originator-tobiosimilar NMS. Indeed, three studies reported on the costs, aside from drug costs alone, associated with a switch program, which highlighted patient funding, program implementation, and the additional staff time required as important costing parameters that should not be overlooked [38-40]. In British Columbia, the Biosimilar Initiative, which supports originatorto-biosimilar NMS, encourages the reimbursement of various fees billable to the Medical Service Plan, including pharmacist and physician visit fees as well as a fee to fund the nursing staff required to support patients with gastrointestinal diseases [47-49]. These fees add to the overall cost of implementing a switch program. While originator-to-biosimilar switch programs may be accompanied by added costs to the healthcare system, it is noteworthy to mention that managed switch programs can be funded through a gain share agreement [44]. Specifically, a gain share agreement is a collaborative arrangement between healthcare commissioners and providers to distribute the resulting cost savings between the stakeholders so that the cost savings can be reinvested by hospitals in patient care [44]. Therefore, the short-term costs associated with a switch program may be outweighed by the long-term benefits to patients if funded through a gain share agreement.

Aside from the costs associated with a switch program, additional factors related to differences in efficacy and safety between originators and biosimilars can also have an impact on the costs associated with originator-to-biosimilar
NMS. The manufacturing of biologic drugs is complex, hence the position of Health Canada about the non-interchangeability of an originator biologic to biosimilar [1]. After NMS, an inadequate response can lead to treatment discontinuation, which is another factor that can be associated with increased total costs, particularly when treatment discontinuation is associated with another treatment switch or adverse events (AEs) requiring medical intervention. Accordingly, Tarallo et al. (2019) determined that the total costs associated with patients who, following initial originator-to-biosimilar NMS, switched back to the reference biologic or to an alternative biologic were consistently greater than the total costs for patients who switched just once [32]. The characteristics associated with treatment discontinuation following originator-to-biosimilar NMS are presented in Table S2 in the electronic supplementary material. Biosimilar discontinuation rates were variable between studies and disease areas ranging from $2.6 \%$ to $38.5 \%$ $[32,35,36,39,42,44,45,50-70]$. Switch-back rates (to the reference biologic) ranged from $0.5 \%$ to $16 \% \quad[7,32,36,41-44,61,63$, $64,67-73]$, while the rate of switching to an alternative drug ranged from $0.9 \%$ to $18.2 \%$ $[32,35,37,39,41,42,45,50,54,55,57,61$, $62,64,67-70]$. Common reasons for discontinuation resulting in a switch included loss of response (LOR) [39, 44, 52-57, 59, 62, 63, 66, $69,70]$, disease activity $[41-43,45,50,51$, 65, 67-69, 72], and AEs [42-45, 51, 53-55, 57, $59-61,63-65,67,69,70,73]$, all of which could be directly associated with additional treatment costs. Moreover, LOR may be addressed through dose escalation prior to discontinuation. For the studies that reported dose escalation, the rates ranged from $2.1 \%$ to $48.5 \%[8,39,45,51$, $54,56,58-62,74]$; however, dose reductions were also reported at a frequency of $8-21.5 \%$ $[8,39,51,59]$. In this study, switching and discontinuation rates for biologic originators by disease area were not captured. However, interestingly, a recent study conducted by Fitzgerald et al. indicated that patients switching from originator to biosimilar infliximab were two to three times more likely to switch to another originator biologic compared to those 
remaining on originator infliximab [75]. While results are variable between studies, these findings validate that, at the very least, there is the potential that a patient who undergoes NMS may subsequently undergo dose escalation, or be switched to an alternative treatment or back to the reference biologic, where multiple switches may be associated with greater total healthcare costs [32]. Along with additional costs associated with HCRU and switch programs, these added elements must also be considered in the decision to adopt a NMS policy.

Subjective reasons such as negative expectations, often referred to as the nocebo effect, can lead to biosimilar discontinuations and should also be considered as a factor that may impact the overall costs post-NMS. The nocebo effect describes negative outcomes with active treatments in the real-world clinical setting, including new or worsening symptoms and AEs, stemming from a patient's negative expectation rather than the pharmacologic action of the treatment itself [76]. The nocebo effect can reduce adherence to biosimilar treatment, particularly in the setting of NMS [22, 76]. To minimize this risk, additional costs related to the education of both patients and healthcare professionals on biosimilars would be necessary. The implementation of such comprehensive education programs should also be taken into account when considering the implementation costs associated with an originator-to-biosimilar NMS policy.

Some governments have discussed and/or announced the implementation of NMS policies [23-26]. While several experts support NMS policies [77, 78], others have voiced their opposition to such "forced" switches for nonmedical reasons [79-81]. Moreover, the Canadian Association of Gastroenterology and Crohn's and Colitis Canada released a joint statement wherein they recommend against infliximab originator-to-biosimilar NMS in patients who have stable CD or UC and who are doing well on the reference biologic [82]. This opinion was formed as a result of data suggesting that switching in this setting leads to an increased risk of LOR, dose escalation, or secondary switching [82]. Importantly, various studies reporting on HCRU and/or costs post-
NMS also reported biosimilar dose escalations and listed LOR as a reason behind treatment discontinuation or secondary switching in patients who were stable prior to NMS (Table S2 in the electronic supplementary material). More recently, the Institut national d'excellence en santé et en services sociaux of Québec published a report on the position of various medical societies, associations, and clinicians with regard to biologic-to-biosimilar NMS policies [83]. It was concluded that, while the use of biosimilars in treatment-naïve patients or as a substitution in patients for a medical reason is generally accepted, the implementation of an originator-to-biosimilar switch for non-medical reasons is not accepted. Accordingly, only two Canadian provinces, namely British Columbia and Alberta, have originator-to-biosimilar NMS policies currently in place. Québec clinicians agree that forcing an originator-to-biosimilar NMS in patients comes with a risk of destabilization to the patient, with a possibility of nonresponse or development of significant adverse events, for whom little treatment options are available [83]. Altogether, the idea of forcing stable patients to switch without a medical reason to a biosimilar drug remains a debatable topic amongst expert groups.

This study is subject to some limitations. First, the studies included in the SLR were limited in number and comprised primarily conference abstracts, highlighting a need for more studies, and subsequent publication of the results, regarding HCRU and/or costs associated with originator-to-biosimilar NMS. Secondly, many of the included studies were funded by pharmaceutical companies, such that the investigated outcomes or results shown may be biased towards the affiliated drug. The variability in the methodologies used by the identified studies may limit the interpretation and generalizability of the synthesized results. Furthermore, the skewed proportion of studies considering infliximab originator-to-biosimilar NMS may limit the generalizability of the current results to other biologics. Similarly, the skewed proportion of studies investigating rheumatological or gastroenterological diseases may also limit the generalizability of the current results to other disease areas. Among the 
identified studies, most are conference abstracts. While conference abstracts allow for the inclusion of studies that have yet to be published, it must be noted that publications from conference proceedings have not undergone a thorough peer-review process, as is required for an article published by a journal. Moreover, as conference abstracts follow a strict word limit, there is often a lack of details and information pertaining to the study. While the risk of bias was assessed for all published journal articles, this assessment was not performed for conference abstracts, which represented most of the included studies. It must also be noted that the ROBINS-I tool, which was used for this SLR, was not considered suitable for all included journal articles. While the Newcastle-Ottawa scale is the preferred tool for the assessment of database studies, the ROBINS-I was used as the majority of included journal articles were cohort-based studies. Future research providing more real-world evidence regarding originatorto-biosimilar NMS is warranted.

\section{CONCLUSION}

This systematic literature review found that the overall economic impact of originator-tobiosimilar NMS in the real-world setting remains uncertain, as drug costs alone, without consideration of the additional HCRU associated with NMS, continue to be the focus of most economic studies. Nevertheless, among the seven studies that reported on the difference in HCRU or costs with and without NMS, all studies showed an increase in healthcare services used and HCRU-related costs associated with NMS. These findings suggest that the expected overall savings generated by an originator-to-biosimilar switch owing to less costly drug prices may be reduced because of an increase in HCRU and its associated costs postswitch. More real-world studies that include both drug costs and additional NMS-related healthcare costs are needed to better evaluate the full economic impact of NMS.

\section{ACKNOWLEDGEMENTS}

Funding. This study was funded by AbbVie Corporation. AbbVie sponsored the study, contributed to the design and to the review, approved the final version and funded the journal's Rapid Service and Open Access Fees. No author has received funding for developing the abstract. No honoraria or payments were made for authorship.

Medical Writing. The authors would like to acknowledge the participation of Christopher Vannabouathong for writing the manuscript. Christopher Vannabouathong has received funding from PeriPharm as a freelance for providing medical writing.

Authorship. All named authors meet the International Committee of Medical Journal Editors (ICMJE) criteria for authorship for this article, take responsibility for the integrity of the work as a whole, and have given their approval for this version to be published.

Author Contributions. JL, CB, EH, KM, and $\mathrm{JB}$, from PeriPharm, have participated in the study conduct, data interpretation, and the approval of the manuscript. DP and YR participated in data interpretation and the approval of the manuscript.

Prior Publication. This systematic literature review was previously presented as a poster at the annual ISPOR meeting, which was held virtually on May 17-20, 2021.

Disclosures. Jean Lachaine and Catherine Beauchemin are partners at PeriPharm, while Erin Hillhouse, Karine Mathurin, and Joëlle Bibeau are employees at PeriPharm, a company that has served as a consultant to AbbVie and has received funding from AbbVie. Yasmine Rahal and Diana Parison are AbbVie employees and have stock/stock options.

Compliance with Ethics Guidelines. This article is based on previously conducted studies and does not contain any studies with human 
participants or animals performed by any of the authors.

Data Availability. Data sharing is not applicable to this article as no datasets were generated or analyzed during the current study..

Open Access. This article is licensed under a Creative Commons Attribution-NonCommercial 4.0 International License, which permits any non-commercial use, sharing, adaptation, distribution and reproduction in any medium or format, as long as you give appropriate credit to the original author(s) and the source, provide a link to the Creative Commons licence, and indicate if changes were made. The images or other third party material in this article are included in the article's Creative Commons licence, unless indicated otherwise in a credit line to the material. If material is not included in the article's Creative Commons licence and your intended use is not permitted by statutory regulation or exceeds the permitted use, you will need to obtain permission directly from the copyright holder. To view a copy of this licence, visit http:// creativecommons.org/licenses/by-nc/4.0/.

\section{REFERENCES}

1. Health Canada. Biosimilar biologic drugs in Canada: fact sheet. https://www.canada.ca/ content/dam/hc-sc/migration/hc-sc/dhp-mps/alt formats/pdf/brgtherap/applic-demande/guides/ Fact-Sheet-EN-2019-08-23.pdf. Accessed 24 Feb 2020

2. Chan HC, Ng SC. Emerging biologics in inflammatory bowel disease. J Gastroenterol. 2017;52(2): 141-50. https://doi.org/10.1007/s00535-016-12830 .

3. Codreanu C, Popescu CC, Mogosan C. Area of residence and socioeconomic factors reduce access to biologics for rheumatoid arthritis patients in Romania. Biomed Res Int. 2018;2018:7458361. https://doi.org/10.1155/2018/7458361.

4. Louis E. Stopping biologics in IBD-what is the evidence? Inflamm Bowel Dis. 2018;24(4):725-31. https://doi.org/10.1093/ibd/izx098.
5. Ooi CJ, Hilmi I, Banerjee R, et al. Best practices on immunomodulators and biologic agents for ulcerative colitis and Crohn's disease in Asia. J Gastroenterol Hepatol. 2019;34(8):1296-315. https:// doi.org/10.1111/jgh.14648.

6. Al Rabayah AA, Hammoudeh S, Mashni O, Hanoun E, Al Qasem W, Al MD. PCN32-the effectiveness and safety of switching from orginal filgrastim to biosimilar filgrastim in primary prophylaxis of chemotherapy induced febrile neutropenia: a retrospective cohort study. Value Health. 2018;21(Supplement 3):S20. https://doi.org/10. 1016/j.jval.2018.09.114.

7. Flodmark CE, Lilja K, Woehling $\mathrm{H}$, Jarvholm K. Switching from originator to biosimilar human growth hormone using dialogue teamwork: singlecenter experience from Sweden. Biol Ther. 2013;3(1):35-43. https://doi.org/10.1007/s13554013-0011-z.

8. Minutolo R, Bolasco P, Chiodini P, et al. Effectiveness of switch to erythropoiesis-stimulating agent (ESA) biosimilars versus maintenance of ESA originators in the real-life setting: matched-control study in hemodialysis patients. Clin Drug Investig. 2017;37(10):965-73. https://doi.org/10.1007/ s40261-017-0562-8.

9. Szlumper C, Laftah Z, Smith C, et al. Bristol cup posters. Brit J Dermatol. 2017;2017(177):25-77. https://doi.org/10.1111/bjd.15426.

10. Bernstein CN, Wajda A, Svenson LW, et al. The epidemiology of inflammatory bowel disease in Canada: a population-based study. Am J Gastroenterol. 2006;101(7):1559-68. https://doi.org/10. 1111/j.1572-0241.2006.00603.x.

11. Eder L, Widdifield J, Rosen CF, et al. Trends in the prevalence and incidence of psoriasis and psoriatic arthritis in Ontario, Canada: a population-based study. Arthritis Care Res (Hoboken). 2019;71(8): 1084-91. https://doi.org/10.1002/acr.23743.

12. Safiri S, Kolahi AA, Hoy D, et al. Global, regional and national burden of rheumatoid arthritis 1990-2017: a systematic analysis of the Global Burden of Disease study 2017. Ann Rheum Dis. 2019;78(11):1463-71. https://doi.org/10.1136/ annrheumdis-2019-215920.

13. Patented Medicine Prices Review Board. Biologics in Canada. Part 1: Market Trends, 2018. https://www. canada.ca/en/patented-medicine-prices-review/ services/reports-studies/biologics-part1-markettrends.html. Accessed 24 Feb 2020.

14. Patented Medicine Prices Review Board. Potential Savings from Biosimilars in Canada. http://www. 
pmprb-cepmb.gc.ca/view.asp?ccid=1304. Accessed 24 Feb 2020.

15. Andrade C. Bioequivalence of generic drugs. J Clin Psychiatry. 2015;76(9):e1130-1. https://doi.org/10. 4088/JCP.15f10300.

16. The Lancet O. Generic drugs: are they the future for affordable medicine? Lancet Oncol. 2018;19(2):149. https://doi.org/10.1016/S1470-2045(18)30033-0.

17. Uhl K, Peters JR. How the FDA ensures high-quality generic drugs. Am Fam Physician. 2018;97(11): 696-7.

18. Kaplan GG, Ma C, Seow CH, Kroeker KI, Panaccione $\mathrm{R}$. The argument against a biosimilar switch policy for infliximab in patients with inflammatory bowel disease living in Alberta. J Can Assoc Gastroenterol. 2020;3(5):234-42. https://doi.org/10.1093/jcag/ gwz044.

19. Barbier L, Ebbers HC, Declerck P, Simoens S, Vulto AG, Huys I. The efficacy, safety, and immunogenicity of switching between reference biopharmaceuticals and biosimilars: a systematic review. Clin Pharmacol Ther. 2020;108(4):734-55. https:// doi.org/10.1002/cpt.1836.

20. Cohen HP, Blauvelt A, Rifkin RM, Danese S, Gokhale SB, Woollett G. Switching reference medicines to biosimilars: a systematic literature review of clinical outcomes. Drugs. 2018;78(4): 463-78. https://doi.org/10.1007/s40265-018-0881y.

21. Dolinar R, Kohn CG, Lavernia F, Nguyen E. The non-medical switching of prescription medications. Postgrad Med. 2019;131(5):335-41. https://doi.org/ 10.1080/00325481.2019.1618195.

22. Fleischmann R, Jairath V, Mysler E, Nicholls D, Declerck P. Nonmedical switching from originators to biosimilars: does the nocebo effect explain treatment failures and adverse events in rheumatology and gastroenterology? Rheumatol Ther. 2020;7(1):35-64. https://doi.org/10.1007/s40744019-00190-7.

23. BC Gov News. B.C. expands use of biosimilars to offer coverage for more treatment options. https:// news.gov.bc.ca/releases/2019HLTH0080-001072. Accessed 24 Feb 2020.

24. Harnett CE. B.C. arthritis, diabetes patients have 6 months to switch to cheaper 'biosimilar' drugs. Times Colonist. https://www.timescolonist.com/ news/local/b-c-arthritis-diabetes-patients-have-6months-to-switch-to-cheaper-biosimilar-drugs- 1 . 23835054. Accessed 24 Feb 2020.
25. Smith M. Why Alberta is making some patients change their medication-and what that means. The Star. https://www.thestar.com/calgary/2019/ 12/12/why-alberta-is-making-some-patientschange-their-medicationand-what-that-means. html. Accessed 25 Feb 2020.

26. Grant K. Drug maker urges patients to speak out as Alberta, Ontario consider switch to cheaper biosimilars. The Globe and Mail. https://www. theglobeandmail.com/canada/article-drug-makerurges-patients-to-speak-out-as-alberta-ontarioconsider/. Accessed 25 Feb 2020.

27. Liu Y, Yang M, Garg V, Wu EQ, Wang J, Skup M. Economic impact of non-medical switching from originator biologics to biosimilars: a systematic literature review. Adv Ther. 2019;36(8):1851-77. https://doi.org/10.1007/s12325-019-00998-3.

28. CADTH. Strings Attached: CADTH's Database Search Filters. https://www.cadth.ca/resources/ finding-evidence/strings-attached-cadths-databasesearch-filters\#rand. Accessed 3 March 2020.

29. Hutton B, Salanti G, Caldwell DM, et al. The PRISMA extension statement for reporting of systematic reviews incorporating network meta-analyses of health care interventions: checklist and explanations. Ann Intern Med. 2015;162(11): 777-84. https://doi.org/10.7326/M14-2385.

30. Statistics Canada. Table 18-10-0005-01 Consumer Price Index, annual average, not seasonally adjusted. https://www150.statcan.gc.ca/t1/tbl1/en/tv. action?pid=1810000501. Accessed 1 Apr 2020.

31. Sterne JA, Hernan MA, Reeves BC, et al. ROBINS-I: a tool for assessing risk of bias in non-randomised studies of interventions. BMJ. 2016;355:i4919. https://doi.org/10.1136/bmj.i4919.

32. Tarallo M, Onishchenko K, Alexopoulos ST. Costs associated with non-medical switching from originator to biosimilar etanercept in patients with rheumatoid arthritis in the UK. J Med Econ. 2019;22(11):1162-70. https://doi.org/10.1080/ 13696998.2019.1652183.

33. Glintborg B, Sorensen J, Hetland ML. Does a mandatory non-medical switch from originator to biosimilar infliximab lead to increased use of outpatient healthcare resources? A register-based study in patients with inflammatory arthritis. RMD Open. 2018;4(2):e000710. https://doi.org/10.1136/ rmdopen-2018-000710.

34. Gibofsky A, Skup M, Yang M, Gao W, Doctor T. Real-world outcomes in stable originator biologictreated adult patients who stayed on the therapy versus those who switched to biosimilar: a retrospective chart review study in Europe. Ann Rheum 
Dis. 2019;78(Supplement 2):1582. https://doi.org/ 10.1136/annrheumdis-2019-eular.4303.

35. Huoponen S, Eberl A, Rasanen P, et al. Health-related quality of life and costs of switching originator infliximab to biosimilar one in treatment of inflammatory bowel disease. Medicine (Baltimore). 2020;99(2):e18723. https://doi.org/10.1097/MD. 0000000000018723 .

36. Phillips K, Juday T, Zhang Q, Keshishian A. Economic outcomes, treatment patterns, and adverse events and reactions for patients prescribed infliximab or CT-p13 in the Turkish population. Ann Rheum Dis. 2017;76(Supplement 2):835. https:// doi.org/10.1136/annrheumdis-2017-eular.2933.

37. Peral C, Valderrama M, Montoro M, Gomez S, Tarallo M. PRM42-cost model of switching from enbrel to etanercept biosimilars, for non medical reasons, in rheumatoid arthritis patients in Spain. Value Health. 2018;21(Supplement 3):S362. https://doi. org/10.1016/j.jval.2018.09.2165.

38. Rahmany S, Cotton S, Garnish S, et al. PTH-157 The introduction of biosimilar infliximab (CT-P13) through a managed switching programme generates significant cost savings with high levels of patient satisfaction. Gut. 2016;65(Suppl 1):A297. https://doi.org/10.1136/gutjnl-2016-312388.560.

39. St. Clai rJones A, Smith M. P527 Infliximab biosimilar switching program overseen by specialist pharmacist saves money, realises investment and optimises therapy. J Crohns Colitis. 2017;11(suppl1):S348-S348. https://doi.org/10.1093/ecco-jcc/ jjx002.651.

40. Barnes T, Wong E, Thakrar K, et al. 106 Switching stable rheumatology patients from an originator biologic to a biosimilar: resource cost in the UK. Rheumatology. 2018;57(suppl_3):82. https://doi. org/10.1093/rheumatology/key075.330.

41. Chan A, Kitchen J, Scott A, Pollock D, Marshall R, Herdman L. Implementing and delivering a successful biosimilar switch programme-the Berkshire West experience. Future Healthc J. 2019;6(2):143-5. https://doi.org/10.7861/futurehosp.6-2-143.

42. Nisar MK. Etanercept biosimilar switch: can it be successful without clinic review? Ann Rheum Dis. 2019;78(Supplement 2):1380-1. https://doi.org/10. 1136/annrheumdis-2019-eular.201.

43. Shah K, Flora K, Penn H. 232 Clinical outcomes of a multi-disciplinary switching programme to biosimilar etanercept for patients with rheumatoid arthritis. Rheumatology. 2018;57(suppl3):iii143-4. https://doi.org/10.1093/rheumatology/key075.456.
44. Razanskaite V, Bettey M, Downey L, et al. Biosimilar infliximab in inflammatory bowel disease: outcomes of a managed switching programme. J Crohns Colitis. 2017;11(6):690-6. https://doi.org/ 10.1093/ecco-jcc/jjw216.

45. Plevris N, Jones GR, Jenkinson PW, et al. Implementation of CT-P13 via a managed switch programme in Crohn's disease: 12-month real-world outcomes. Dig Dis Sci. 2019;64(6):1660-7. https:// doi.org/10.1007/s10620-018-5406-8.

46. Mathurin K, Castonguay A, Parison D, Rahal Y, Lachaine J, Beauchemin C. Economic impact of originator-to-biosimilar non-medical switching on health care resource utilization in rheumatic patients in Quebec, Canada. 2021.

47. British Columbia PharmaCare. Biosimilars initiative: prescriber guide-rheumatologists. 2020. https://www2.gov.bc.ca/assets/gov/health/healthdrug-coverage/pharmacare/biosimrheumguide.pdf.

48. British Columbia PharmaCare. Biosimilars initiative: prescriber guide-gastroenterologists and internal medicine specialists. 2020. https://www2. gov.bc.ca/assets/gov/health/health-drug-coverage/ pharmacare/biosimgastroguide.pdf.

49. British Columbia PharmaCare. Biosimilars initiative: pharmacy guide rituximab. 2020.https:// www2.gov.bc.ca/assets/gov/health/health-drugcoverage/pharmacare/biosimpharmguidertx.pdf.

50. Ala K, Avery P, Wilson R, et al. PTU-059 early experience with biosimilar infliximab at a district general hospital for an entire crohns disease patient cohort switch from remicade to inflectra. Gut. 2016;65(Suppl 1):A81-A81. https://doi.org/10. 1136/gutjnl-2016-312388.145.

51. Bergqvist V, Kadivar M, Molin D, et al. Switching from originator infliximab to the biosimilar CT-P13 in 313 patients with inflammatory bowel disease. Therap Adv Gastroenterol. 2018;11(no pagination): 1756284818801244. https://doi.org/10.1177/ 1756284818801244 .

52. Diaz Hernandez L, Rodriguez Gonzalez GE, Vela Gonzalez M, et al. Efficacy and safety of switching between originator and biosimilar infliximab in patients with inflammatory bowel disease in practical clinic: results to 6 months. J Crohn's Colitis. 2016;10(Supplement 1):S327. https://doi.org/10. 1093/ecco-jcc/jjw019.

53. Fischer S, Klenske E, Schmitt H, et al. UEG week 2018 poster presentations. United Eur Gastroenterol J. 2018;6(S8):A651. https://doi.org/10.1177/ 2050640618792819. 
54. Guerra Veloz MF, Belvis Jimenez M, Valdes Delgado $\mathrm{T}$, et al. Long-term follow up after switching from original infliximab to an infliximab biosimilar: realworld data. Therap Adv Gastroenterol. 2019;12(no pagination):1756284819858052. https://doi.org/ $10.1177 / 1756284819858052$.

55. Hoivik ML, Buer LCT, Cvancarova $M$, et al. Switching from originator to biosimilar infliximab-real world data of a prospective 18 months follow-up of a single-centre IBD population. Scand J Gastroenterol. 2018;53(6):692-9. https://doi.org/ 10.1080/00365521.2018.1463391.

56. Rodríguez Glez GE, Díaz Hernández L, Morales Barrios JA, et al. P629 Efficacy, safety and economic impact of the switch to biosimilar of infliximab in inflammatory bowel disease patients in clinical practice: results of one year. J Crohn's Colitis. 2017;11(suppl_1):S402-S402. https://doi.org/10. 1093/ecco-jcc/jjx002.753.

57. Sieczkowska J, Jarzebicka D, Banaszkiewicz A, et al. Switching between infliximab originator and biosimilar in paediatric patients with inflammatory bowel disease. J Crohns Colitis. 2016;10(2):127-32. https://doi.org/10.1093/ecco-jcc/jjv233.

58. Kang B, Lee K, Choe YH. P542 Long-term outcomes after switching from originator infliximab to biosimilar in paediatric-onset inflammatory bowel disease patients: a single centre prospective observational study. J Crohn's Colitis. 2017;11(suppl1): S355-6. https://doi.org/10.1093/ecco-jcc/jjx002. 666.

59. Smits LJT, Grelack A, Derikx L, et al. Long-term clinical outcomes after switching from Remicade(®) to biosimilar CT-P13 in inflammatory bowel disease. Dig Dis Sci. 2017;62(11):3117-22. https://doi.org/10.1007/s10620-017-4661-4.

60. Park SH, Kim YH, Lee JH, et al. Post-marketing study of biosimilar infliximab (CT-P13) to evaluate its safety and efficacy in Korea. Expert Rev Gastroenterol Hepatol. 2015;9(Supplement 1):35-44. https://doi.org/10.1586/17474124.2015.1091309.

61. Ratnakumaran R, To N, Gracie DJ, et al. Efficacy and tolerability of initiating, or switching to, infliximab biosimilar CT-P13 in inflammatory bowel disease (IBD): a large single-centre experience. Scand J Gastroenterol. 2018;53(6):700-7. https://doi.org/ 10.1080/00365521.2018.1464203.

62. Gervais L, McLean LL, Wilson ML, et al. Switching from originator to biosimilar infliximab in paediatric inflammatory bowel disease is feasible and uneventful. J Pediatr Gastroenterol Nutr. 2018;67(6):745-8. https://doi.org/10.1097/MPG. 0000000000002091.
63. Dyball S, Hoskins V, Christy-Kilner S, Haque S. Effectiveness and tolerability of Benepali in rheumatoid arthritis patients switched from enbrel. Arthritis Rheumatol. 2017;69(Supplement):no pagination.

64. Nisar MK. 204 Switching to biosimilar rituximab: a real world study. Rheumatology. 2019;58(Supplement 3):125-6. https://doi.org/10.1093/ rheumatology/kez107.020.

65. Ma J, Petford S, Jones L, Douglas K, John H. 064 Audit of the clinical efficacy and safety of etanercept biosimilar to its reference product in patients with inflammatory arthritis: experience from a district general hospital in the United Kingdom. Rheumatology. 2018;57(Supplement 3):64. https:// doi.org/10.1093/rheumatology/key075.288.

66. Nascimento Junior RR. Clinical and economic "real world" analysis of the switching from remicade (infliximabe) by remsima (infliximab biossimilar) of planserv patients with rheumatoid arthritis, ankylosing spondylitis and psoriatic arthritis. Value Health. 2018;21:S297-8.

67. Valido A, Silva-Dinis J, Saavedra MJ, et al. Efficacy, immunogenicity and cost analysis of a systematic switch from originator infliximab to biosimilar CTP13 of all patients with inflammatory arthritis from a single center, efficacy, immunogenicity and cost analysis of a systematic switch from originator infliximab to biosimilar CT-P13 of all patients with inflammatory arthritis from a single center. Acta Reumatol Portuguesa. 2019;22:1.

68. Ahmad N, Morsley K, Allard A, et al. E014 Patient experience of switching to biosimilar Benepali. Rheumatology. 2019;58(Supplement_3):166. https://doi.org/10.1093/rheumatology/kez110.013.

69. Abdalla A, Byrne N, Conway R, et al. Long-term safety and efficacy of biosimilar infliximab among patients with inflammatory arthritis switched from reference product. Open Access Rheumatol. 2017;9: 25.

70. Gutermann L, Apparuit M, Boissinot L, et al. Evaluation of infliximab (remicade) substitution by infliximab biosimilar (inflectra): cost savings and therapeutic maintenance. Eur J Hosp Pharm. 2017;24(Supplement 1):A67-8. https://doi.org/10. 1136/ejhpharm-2017-000640.149.

71. Alkoky H, Pakozdi A, Tahir H. 2018 ACR/ARHP annual meeting abstract supplement. Arthritis Rheumatol. 2018;70(Suppl 9):1-3553. https://doi. org/10.1002/art.40700.

72. Uke PC, Morris C, Chitale S, James J, Miller H, Gladston-Chelliah E. E007 Etanercept (ETN) biosimilar (Benapali-SB4) switches in inflammatory 
arthritis patients at Wrightington Hospital. Rheumatology. 2019;58(Supplement 3):iii164. https://doi.org/10.1093/rheumatology/kez110.006.

73. Sheppard M, Hadavi S, Hayes F, Kent J, Dasgupta B. AB0322 preliminary data on the introduction of the infliximab biosimilar (CT-P13) to a real world cohort of rheumatology patients. Ann Rheum Dis. 2016;75(Suppl 2):1011. https://doi.org/10.1136/ annrheumdis-2016-eular.5252.

74. Ramos RJ. Safety and effectiveness of switching to infliximab biosimilar in digestive and rheumatological pathology. Eur J Hosp Pharm. 2018;25(Supplement 1):A203-4. https://doi.org/10.1136/ ejhpharm-2018-eahpconf.438.

75. Fitzgerald $\mathrm{T}$, Melsheimer R, Lafeuille $\mathrm{MH}$, et al. Switching and discontinuation patterns among patients stable on originator infliximab who switched to an infliximab biosimilar or remained on originator infliximab. Biologics. 2021;15:1-15. https://doi.org/10.2147/BTT.S285610.

76. Colloca L, Panaccione R, Murphy TK. The clinical implications of nocebo effects for biosimilar therapy. Front Pharmacol. 2019;10:1372. https://doi. org/10.3389/fphar.2019.01372.

77. Kay J, Schoels MM, Dorner T, et al. Consensusbased recommendations for the use of biosimilars to treat rheumatological diseases. Ann Rheum Dis. 2018;77(2):165-74. https://doi.org/10.1136/ annrheumdis-2017-211937.

78. Crosby M, Tadrous M, Gomes T. Potential cost implications of mandatory non-medical switching policies for biologics for rheumatic conditions and inflammatory bowel disease in Canada. Clin Pharmacol Ther. 2021;109(3):739-45. https://doi.org/ 10.1002/cpt.2042.

79. Gentileschi S, Barreca C, Bellisai F, et al. Switch from infliximab to infliximab biosimilar: efficacy and safety in a cohort of patients with different rheumatic diseases. Response to: Nikiphorou E, Kautiainen $\mathrm{H}$, Hannonen $\mathrm{P}$, et al. Clinical effectiveness of CT-P13 (Infliximab biosimilar) used as a switch from Remicade (infliximab) in patients with established rheumatic disease. Report of clinical experience based on prospective observational data. Expert Opin Biol Ther. 2015;15:1677-1683. Expert Opin Biol Ther. 2016;16(10):1311-2. https://doi. org/10.1080/14712598.2016.1198765.

80. McKinnon R, Ward M. Safety considerations of biosimilars. Aust Prescr. 2016;39(6):188-9. https:// doi.org/10.18773/austprescr.2016.084.
81. Crohn's and Colitis Canada. Patient and health care provider input: non-medical biosimilar switch policy for patients with inflammatory bowel disease. 2019. http://www.crohnsandcolitis.ca/Crohns_ and_Colitis/documents/2019-September-

CCCPatient-HCP-Survey-Input-Full-Report.pdf.

82. Moayyedi P, Benchimol EI, Armstrong D, Yuan C, Fernandes A, Leontiadis GI. Joint Canadian Association of Gastroenterology and Crohn's Colitis Canada position statement on biosimilars for the treatment of inflammatory bowel disease. J Can Assoc Gastroenterol. 2020;3(1):e1-9. https://doi. org/10.1093/jcag/gwz035.

83. Institut national d'excellence en santé et en services sociaux (INESSS). Innocuité de la substitution et de l'interchangeabilité des médicaments biologiques. État des connaissances rédigé par Isabelle Dufort, Émilie Viel et Stéphane Gilbert. Québec, Qc : INESSS; 2020. 79 p.https://www.inesss.qc.ca/ fileadmin/doc/INESSS/Rapports/Medicaments/ INESSS_Biosimilaires_EC.pdf.

84. O'Brien GL, Carroll DG, Walshe V, et al. PGI34-a cost saving measure from the utilisation of biosimilar infliximab in the Irish secondary care setting. Value Health. 2018;21(Supplement 3):S147. https://doi.org/10.1016/j.jval.2018.09.876.

85. Geccherle A, Tessari R, Variola A, Massella A, Capoferro E, Zuppini T. 7th national congress of the Italian Society of Colorectal Surgery: Rome, September 30-October 3, 2017 Presidents: Claudio Coco, Claudio Mattana, Carlo Ratto. Tech Coloproctol. 2017;21(10):823-45. https://doi.org/10. 1007/s10151-017-1674-0.

86. Kim NH, Park DI, Kim YS, et al. APDW 2018 E-poster exhibitions-lower GI. J Gastroenterol Hepatol. 2018;33(S4):447-531. https://doi.org/10. 1111/jgh.14488.

87. Dayer PVC, Sara JR, Belando CG, et al. Switching of etanercept in a monographic consultation of biosimilar clinical practice and economic cost. Ann Rheum Dis. 2019;78(Supplement 2):2062. https:// doi.org/10.1136/annrheumdis-2019-eular.7911.

88. Moron R, Nieto Gomez P, Garcia Fernandez C, Alvarez SR. 47th ESCP symposium on clinical pharmacy personalised pharmacy care. Int J Clin Pharm. 2019;41(1):289-383. https://doi.org/10. 1007/s11096-018-0759-9.

89. Zahorian T, Farraye FA, Reich J, Noronha A, Wasan SK, Shah B. Successful transition to an infliximab biosimilar at an academic hospital. Am J Gastroenterol. 2018;113:S655-6. 